\title{
A Estruturação do Rol de Oportunidades de Visitação no Parque Nacional da Chapada dos Veadeiros (GO)
}

\section{The Structuring of the List of Visiting Opportunities in the National Park of Chapada dos Veadeiros (GO, Brazil)}

\author{
Thamyris Carvalho Andrade, Thiago do Val Simardi Beraldo Souza, \\ André de Almeida Cunha
}

\begin{abstract}
RESUMO: Este artigo versa sobre a aplicação do método do Rol de Oportunidades de Visitação em Áreas Protegidas - ROVUC [recentemente atualizado e validado pelo Instituto Chico Mendes de Conservação da Biodiversidade - ICMBio] no Parque Nacional da Chapada dos Veadeiros - PNCV. Seu objetivo foi identificar ações prioritárias de planejamento do uso público que subsidiem a construção do Plano de Uso Público da referida Unidade de Conservação - UC. Para a coleta de dados foram realizadas oficinas com a participação de alguns atores sociais, a saber: gestores da UC e guias de Turismo atuantes na região. Sua justificativa se dá pela expansão da área de extensão do PNCV que associada ao crescente fluxo de visitação dos últimos dez anos reforçou a necessidade de um levantamento de subsídios que auxiliem em seu planejamento por se tratar de uma área de Cerrado de acentuado interesse ecológico. A partir dos procedimentos realizados e aqui descritos identificou-se que a diversificação das oportunidades é uma aliada para a gestão do PNCV, no que tange à oportunização do visitante não somente à realização de uma determinada atividade, mas sim, o favorecimento de uma experiência.
\end{abstract}

PALAVRAS CHAVE: Turismo; Áreas Protegidas; Parques Nacionais; ROVUC.

ABSTRACT: This paper deals with the application of the Recreation Opportunity Spectrum, in the Chapada dos Veadeiros Brazilian National Park - PNCV, based on an adaptation of ROS to the Brazilian context, the ROVUC [recently updated and validated by the Chico Mendes Institute for Biodiversity Conservation - ICMBio], to identify priority actions for public use planning. Data collection was realized in workshops with PNCV managers and experienced tour guides in the region. This works is justified due to the recent expansion of the PNCV area, including new natural resources for visitation, together with the intense increase in visitors flow in the last years. Thus, we aim to contribute to the planning process of public use in the PNCV, an important area of the Cerrado biome in terms of ecological interest. Current and potential activities identified by guides were much more diverse from those identified by official documents. Most of the ROVUC attributes were classified as pristine or natural, the main characteristic of PNCV. However, the diversification of opportunities in some attractions might be a good strategy to receive different types of visitors, seeking for more facilities and services. We strongly recommend the integrated work of managers, researchers and the tourism trade to improve visitor's planning process for protected areas, and also the use and revision of ROVUC attributes, as suggested here, in future applications.

KEYWORDS: Tourism; Protected Areas; National Parks; ROVUC. 


\section{Introdução}

Com a expansão do turismo de natureza, especialmente em países em desenvolvimento, torna-se maior a necessidade de se estabelecer limites e alinhamentos mais precisos em relação a essa prática. Por se tratar de ambientes ricos em biodiversidade e de áreas naturais sensíveis, a gestão da visitação em áreas naturais protegidas é considerada uma missão complexa.

Aliar as necessidades de conservação com os anseios dos praticantes de turismo de natureza é um dos desafios dos gestores quando se trata de uso público em áreas naturais. No Brasil, as áreas naturais protegidas são regidas por leis pouco específicas em relação ao uso público, ficando, por vezes, a cargo do gestor se aproximar destes praticantes para a criação e estabelecimento de normas e posturas em relação a essa prática.

Esse planejamento, bem como suas normas, se apresenta no Plano de Manejo, especificamente no Plano de Uso Público, documento que deve ser constantemente atualizado, a depender das necessidades e da dinâmica da unidade. E num momento em que a globalização avança e as oportunidades crescem, o visitante também se torna mais exigente em relação ao produto que consome, aumentando suas expectativas e gerando novas necessidades de planejamento.

Nesse sentido, pesquisadores e gestores passaram a observar o comportamento do turista em áreas naturais no intuito de atender estes novos anseios ao passo de manter a fiel execução dos objetivos do uso público. Desenvolver um bom planejamento em áreas protegidas para garantir a construção sustentável do ecoturismo é uma iniciativa que visa cooperar com a conservação das Unidades de Conservação - UC e toda a sua sociobiodiversidade.

Dentre os estudos sobre essa temática está o Rol de Oportunidades de Visitação em Unidades de Conservação - ROVUC que se apresenta como um método de diversificação de oportunidades e compreende que o turista tem a necessidade não somente de realizar atividades específicas, mas sim, experiências completas.

Compreendendo a relação direta e necessária entre ecoturismo, planejamento e áreas naturais, para este estudo adotou-se a concepção de ecoturismo como o Turismo que é praticado em áreas naturais com o comprometimento de conservar o meio ambiente e garantir uma possível harmonia entre as comunidades locais.

Em Parques Nacionais, Unidades de Conservação de Proteção Integral, as normas de uso público são responsáveis pela movimentação de pessoas e tem como objetivo, "a preservação de ecossistemas naturais de grande relevância ecológica e beleza cênica, possibilitando a realização de pesquisas científicas e o desenvolvimento de atividades de educação e interpretação ambiental, de recreação em contato com a natureza e de turismo ecológico."(BRASIL, 2000). Para além da conservação ambiental, este tipo de UC contempla a visitação como aliada para a disseminação da prática de lazer em áreas naturais, para a disseminação de políticas de educação ambiental e até mesmo para questões relacionadas à saúde do corpo e da mente.

A Chapada dos Veadeiros é uma região que visa cumprir o estratégico e importante papel de conservação do bioma Cerrado, que representa cerca de $22 \%$ do território nacional. Destaca-se que o Cerrado é considerado um dos hotspots ${ }^{1}$ mundiais de biodiversidade por apresentar abundância de espécies endêmicas e por 
lidar com uma perda elevada do habitat anualmente. Logo, a necessidade de sua conservação é urgente.

Em se tratando de uma área de grande interesse para a conservação da biodiversidade, o Parque Nacional da Chapada dos Veadeiros é uma Unidade de Conservação como tantas outras no Brasil, que exige da gestão do ICMBio uma atenção e um comprometimento com o planejamento intenso para conciliar os interesses da conservação ambiental, das comunidades nativas e dos anseios dos praticantes do turismo de natureza.

De 625mil hectares [quando em sua criação por meio do Decreto 49.875 de 1961] para 240.611 hectares [ampliação por meio do decreto de 05 de junho em 2017] com a expansão de sua área de abrangência, cresceu também a necessidade de subsídios e pesquisas que auxiliem na construção do Plano de Uso Público da unidade.

Neste sentido, o presente artigo tem por objetivo geral, avaliar o Rol de Oportunidades de Visitação dos principais atrativos do PARNA Chapada dos Veadeiros (PNCV) para subsidiar ações prioritárias de planejamento de uso público. Para alcançar tal objetivo valeu-se dos seguintes objetivos específicos:

- Inventariar as diferentes oportunidades de visitação, através das atividades existentes e potenciais;

- Classificar os atrativos por meio do método ROVUC;

- Orientar a diversificação da oferta de visitação;

- Subsidiar a construção de um Plano de Uso Público capaz de promover o manejo e a viabilização da diversificação das experiências de visitação.

Desta forma, a partir dos objetivos acima traçados, a pesquisa desenvolve-se de modo a encontrar caminhos e respostas para amparar a construção de um plano de uso público eficaz e exequível para o PARNA Chapada dos Veadeiros por meio da aplicação do método ROVUC.

\section{Materiais e métodos}

\section{Área de estudo}

O Parque Nacional da Chapada dos Veadeiros (PNCV) juntamente com o Parque Estadual de Terra Ronca e o Parque Municipal de Itiquira constituem uma das principais áreas da Reserva da Biosfera Goyaz (Figura 1). Localizada na extensão do vale do rio Paranã, a RESBIO Goyaz representa uma das áreas de maior biodiversidade existentes no país (UNESCO, 2008) e abrange o norte e o nordeste goiano com $54.393 \mathrm{Km}^{2}$.

A Reserva abrange uma zona núcleo representada pelo mosaico de três Unidades de Conservação: o Parque Nacional Chapada dos Veadeiros (PNCV), o Parque Estadual Terra Ronca (PETR) e o Parque Municipal de Itiquira (PMI); e suas respectivas zonas de amortecimento delimitadas pelas Áreas de Proteção Ambiental (APA) - APA de Pouso Alto, de Terra Ronca e das Nascentes do Rio Vermelho, respectivamente, contemplando 25 municípios, considerados como zona de transição (NASCIMENTO, BRITO, ÁVILA, MELO, 2016, p.32,) 


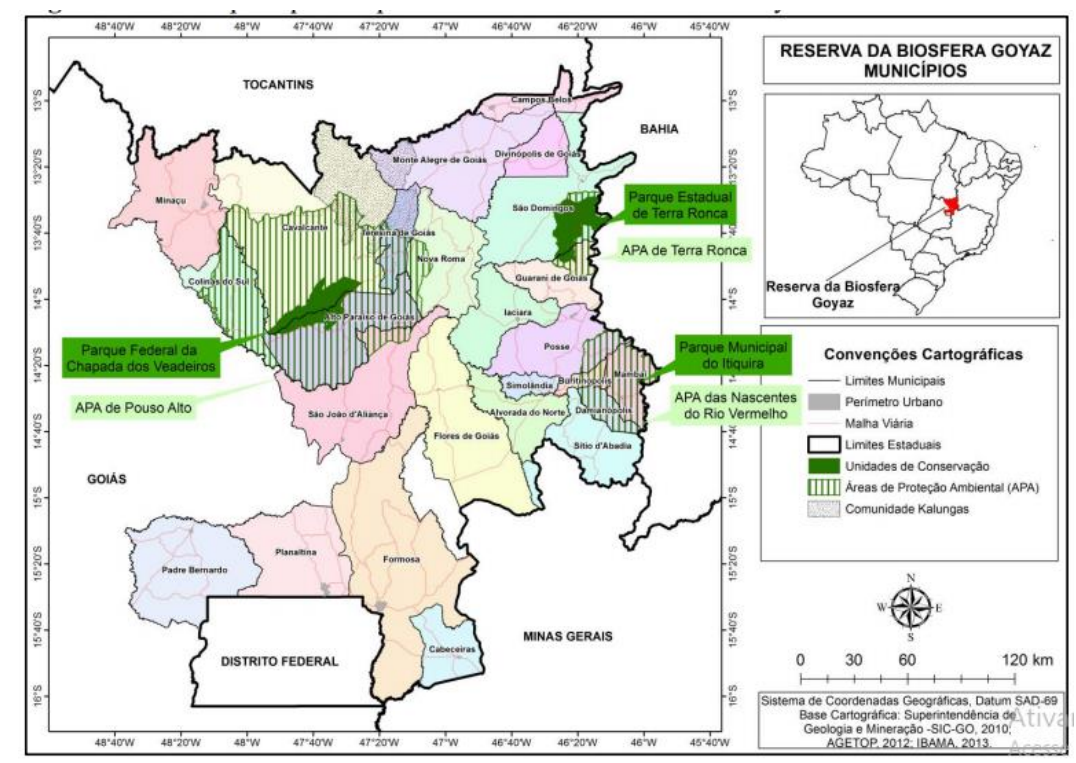

Figura 1: Mapa da Reserva da Biosfera.

Figure 1: Map of the Biosphere Reserve.

Fonte: Nascimento, Brito, Ávila e Melo (2016).

Source: Nascimento, Brito, Ávila and Melo (2016).

Outras importantes Unidades de Conservação localizadas na parte central do bioma Cerrado são a Área de Proteção Ambiental - APA do Pouso Alto (Figura 2), a Terra Indígena Avá Canoeiro, o território quilombola Kalunga, além de dezenas de Reservas Particulares do Patrimônio Natural - RPPN's (ICMBio, 2009). A APA de Pouso Alto circunda o PNCV e é "destinada a fomentar o desenvolvimento sustentável e a preservar a flora, a fauna, os mananciais, a geologia e o paisagismo da região de Pouso Alto, localizada na Chapada dos Veadeiros" (BRASIL, 2001).

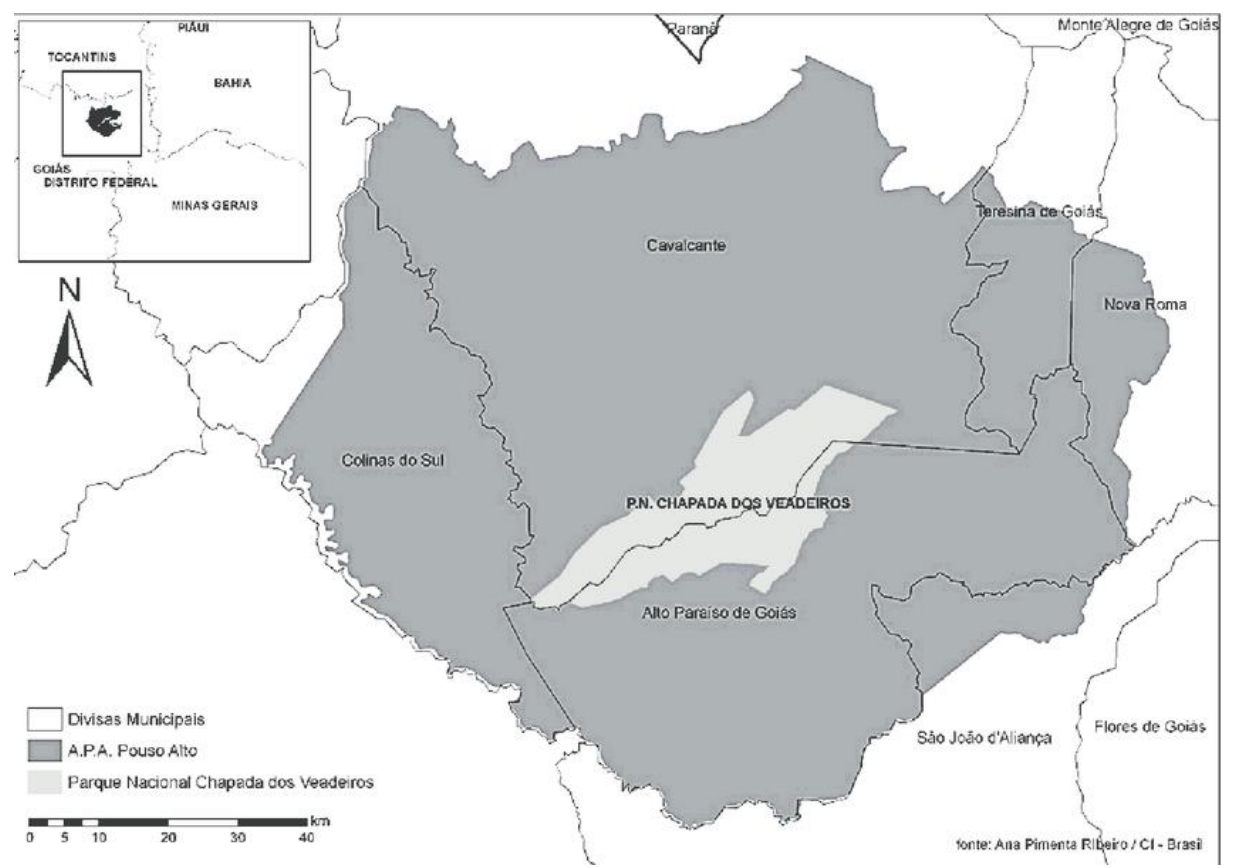

Figura 2: Mapa da APA do Pouso Alto.

Figure 2: Pouso Alto APA map.

Fonte: CI Brasil (2007), adaptado por Lima e Franco (2013).

Source: Cl Brasil (2007), adapted by Lima and Franco (2013). 
O PNCV foi criado no ano de 1961, como Parque Nacional do Tocantins, com o objetivo de proteger áreas de admirável beleza cênica, recursos hídricos e fauna e flora característicos do Cerrado, protegendo, principalmente, o ponto culminante do Planalto Central (ANDRADE, 2014). No princípio, possuía 625mil hectares, mas nos anos de 1972 e 1981 teve sua área suprimida para 171.924 hectares e 65mil hectares, respectivamente. No ano de 2001 quando reconhecido como Sítio do Patrimônio Natural da Humanidade pela UNESCO, sua área foi ampliada para 235mil ha, mas o decreto foi suspenso um ano depois, por alegadas falhas processuais, voltando assim a 65 mil há, ou seja $10 \%$ de sua área original.

O reconhecimento pela UNESCO trouxe ainda mais visibilidade para o PNCV, com isso, ambientalistas, gestores ambientais e parte da população local buscou apoio e defendeu a ampliação do PARNA Chapada dos Veadeiros, particularmente face as ameaças da expansão do agronegócio, da especulação imobiliária e das monoculturas na região. Nesse contexto, no ano de 2017, a unidade teve sua área novamente ampliada para 240.611 ha (BRASIL, 2017). A Figura 3 representa os novos limites da Unidade.

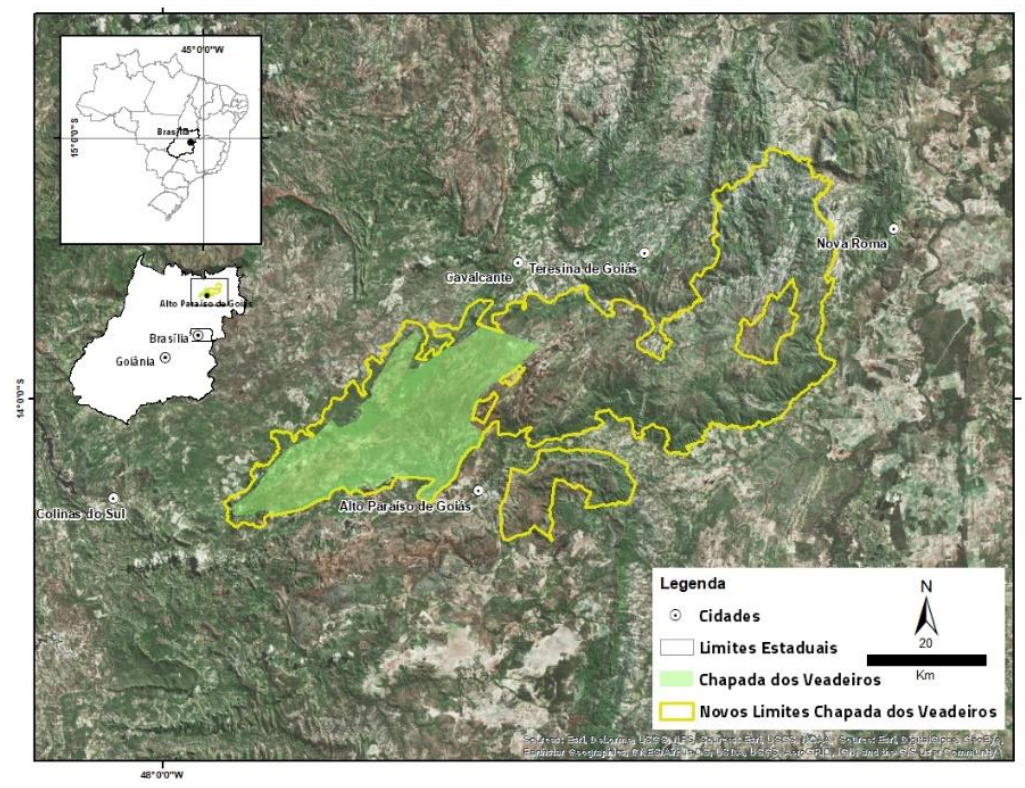

Figura 3: Mapa da área de expansão do PARNA Chapada dos Veadeiros. Figure 3: Map of the expansion area of PARNA Chapada dos Veadeiros.

Fonte: WWF - Brasil (2017).

Source: WWF - Brazil (2017).

A sede do Parque está localizada a $260 \mathrm{~km}$ da capital federal, Brasília, e a $460 \mathrm{~km}$ da capital do estado, Goiânia. Com a expansão de 2017, a UC passou a compreender o território dos municípios de Alto Paraíso de Goiás, Cavalcante, Nova Roma, Teresina de Goiás e São João da Aliança (BRASIL, 2017). Essa ampliação representou um ganho considerável para a biodiversidade e para conservação do bioma Cerrado. A região abriga cerca de 17 espécies da flora e 32 espécies da fauna ameaçadas de extinção, dentre elas estão o Tamanduá-bandeira- Myrmecophaga tridactyla, a Onça pintada - Panthera onca e o Lobo-guará - Chrysocyon brachyurus. O patrimônio natural da área ampliada abrange também áreas com belezas cênicas singulares, trazendo novas oportunidades para o turismo e recreação, assim como novos desafios para a gestão (ICMBio, 2018). 


\section{Coleta de dados}

O movimento de afirmação do território da Chapada dos Veadeiros e do PNCV como importância única para a conservação da natureza e desenvolvimento do turismo sustentável vem sendo consolidado com diversas parcerias. Dentre estas, o Centro UnB Cerrado (vínculo direto da autora enquanto pós-graduanda no Curso de Especialização em Sociobiodiversidade e Sustentabilidade no Cerrado), o Laboratório de Biodiversidade e Áreas Protegidas - LABAP do Departamento de Ecologia, ambos da Universidade de Brasília e a gestão do PARNA Chapada dos Veadeiros, vêm trabalhando em prol de pesquisas aplicadas para a conservação da biodiversidade $\mathrm{e}$ o desenvolvimento do ecoturismo na região. Em função disso, ressalta-se que os dados aqui apresentados são resultado de um trabalho coletivo em parceria com o Parque Nacional, tanto com a equipe gestora, como com os guias de turismo e condutores ambientais locais.

Este artigo foi desenvolvido nesse contexto, buscando subsidiar o Plano de Uso Público (PUP) do PNCV, um dos instrumentos mais importantes para o planejamento de uma UC. O PUP compõe e complementa o Plano de Manejo e apresenta o planejamento das atividades destinadas ao público visitante em harmonia com os objetivos da UC.

Numa perspectiva exploratória e descritiva, a construção desse artigo percorreu os caminhos da pesquisa qualitativa por meio do estudo de caso e de procedimentos bibliográficos, documentais e de campo. Na busca pela valorização da prática do campo buscou-se aportes na experiência dos guias de turismo da Chapada dos Veadeiros em relação às suas percepções frente à realidade existente no Parque Nacional da Chapada dos Veadeiros.

Após a definição de uma lista de atrativos a ser trabalhada, e da identificação das atividades atuais e potenciais para cada um deles, foi feita a classificação de cada atrativo de acordo com os parâmetros, ou atributos do Rol de Oportunidades de Visitação em Unidades de Conservação - ROVUC (ICMBio, 2018). Esta abordagem tem por base o conceito de ROS (Espectro de Oportunidades Recreativas), um método consolidado e validado por pesquisadores e gestores desde meados do século XX, nos parques dos Estados Unidos. O ROS ou ROVAP pode ser utilizado para diferentes objetivos, como; inventariar, planejar, avaliar ações de manejo, e conciliar demandas e oportunidades para a recreação em áreas naturais (CLARK; STANKEY, 1979). Assim, busca proporcionar atividades recreativas específicas para os visitantes, em diferentes cenários ou ambientes, resultando em experiências e benefícios distintos, em busca de atender as expectativas e satisfazer os usuários dos parques.

Além da diversificação da experiência, foi observado que "não existia um visitante ou turista típico", capaz de compor um único perfil, logo seria interessante explorar uma variedade de oportunidades e espaços que atendessem à diferentes demandas de pessoas e perfis (CLARK; STANKEY, 1979, ICMBio, 2018).

$O$ estudo apontou ainda que a satisfação gerada nas pessoas por atividades recreativas era benéfica não só para fins pessoais e sociais como para melhorar a saúde, intensificar a produção no trabalho, propiciar harmonia familiar e gerar consciência ambiental. Em função desses estudos e do anseio de alguns pesquisadores em reconhecer o "Ecoturismo" e a "Recreação" como um tema primordial no manejo das áreas protegidas, o ROS (Recreation Opportunity Spectrum) foi consolidado, pelo 
Serviço Florestal Americano, no final da década de 1970, a partir de experiências anteriores (MCCOOL; STANLEY, 1975, CLARK; STANLEY, 1979). Basicamente, é focado em uma visão de enxergar as diferentes oportunidades de recreação em um gradiente, um rol de Classes de Oportunidades, desde ambientes primitivos com pouca ou nenhuma infraestrutura até áreas com infraestrutura e serviços mais desenvolvidos. Essas classes de oportunidades de recreação foram categorizadas de acordo com suas características biofísicas, sociais e de manejo (ICMBio, 2018)

O ROS tem sido amplamente utilizado em diferentes contextos e países ao redor do mundo. Além da ampla aplicação em áreas protegidas dos Estados Unidos (Moore et al, 2003), a abordagem foi aplicada em diferentes contextos ao redor do mundo, como Noruega (KALTENBORN; LARS, 2003), Nova Zelândia (JOYCE; SUTTON, 2009), China (XIAO et al., 2012), Japão (OISHI, 2013), Canada (HARSHAW; SHEPPARD, 2013), entre outros. No Brasil, a abordagem foi aplicada para compreender as tipologias gerais dos parques e florestas nacionais, desde UCs mais primitivas até aquelas em contextos urbanos (SOUZA et al. 2018). E em 2018, foi elaborado um roteiro adequado às especificidades do contexto brasileiro, do Sistema Nacional de Unidades de Conservação - SNUC, como uma ferramenta para guiar a classificação de recursos e atrativos dentro de uma área protegida e/ou seu entorno, visando subsidiar os processos de planejamento das áreas protegidas do país, o Rol de Oportunidades de Visitação em Unidades de Conservação - ROVUC (ICMBio, 2018). Assim como o ROS, o ROVUC compreende que a satisfação do visitante é resultado de quatro fatores fundamentais: "experiências" "atividades", "benefícios" e "atributos". (ICMBio, 2018), de modo que:

Esses fatores se relacionam, uma vez que os visitantes buscam realizar "atividades" em "ambientes" que Ihes permitem obter as "experiências" desejadas, produzindo "benefícios" pessoais, sociais, econômicos e ambientais. Dessa forma, as motivações de um visitante não são as atividades em si mesmas, mas uma combinação de fatores. Assim, o ROVUC propõe que o planejamento da visitação deve ser baseado nas experiências que desejamos oferecer (ROVUC, 2018).

Nesse contexto, visando identificar, classificar e compreender a diversidade de atrativos do PNCV, o presente trabalho foi realizado em três momentos: (1) planejamento dos objetivos e etapas do trabalho; (2) reuniões de alinhamento e aprimoramento junto à equipe de uso público do PNCV; (3) realização das oficinas. Nas oficinas, foram coletados dados relacionados à três etapas previstas no ROVUC (ICMBio, 2018) (Figura 4).

\begin{tabular}{|c|c|}
\hline Etapa I & - Caracterização do potencial de uso público do PARNA Chapada dos Veadeiros \\
\hline Etapa II & -Inventário dos Atrativos e atividades do PARNA Chapada dos Veadeiros \\
\hline Etapa III & - Caracterização e classificação dos atrativos ou áreas de visitação \\
\hline
\end{tabular}

Figura 4: Sistematização das etapas da pesquisa.

Figure 4: Systematization of the research stages. 
Além destas três etapas adotadas para este estudo (Figura 4), a abordagem propõe outros dois estágios que são: 4 - a identificação das zonas de manejo onde se inserem os atrativos; e 5 - a análise dos dados e espacialização das classes de experiência no mapa da UC (ICMBio, 2018). Estas duas últimas etapas não foram apresentadas neste estudo, embora sejam estágios importantes a serem adotados no Plano de Uso Público, mas que serão conduzidos em momento posterior, coordenado pela equipe do PNCV. Abaixo são detalhados os passos metodológicos para cada uma das três etapas (Figura 5):

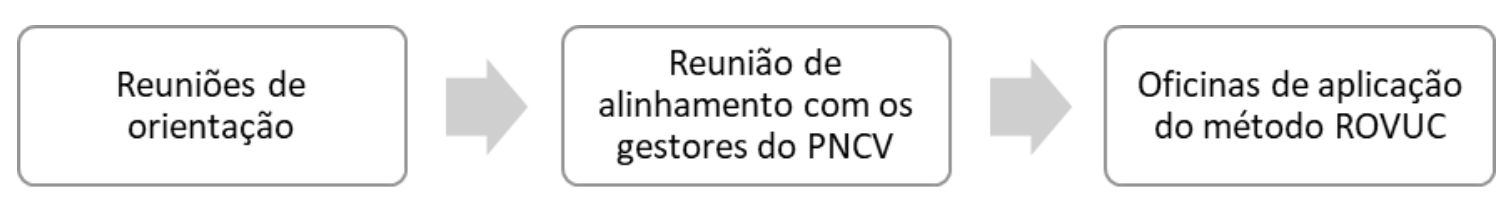

Figura 5: Sistematização das etapas de trabalho.

Figure 5: Systematization of work steps.

\section{Etapa I_Caracterização do Potencial de Uso Público do PARNA Chapada dos Veadeiros}

A etapa de caracterização do potencial de Uso público foi realizada a partir da combinação dos principais documentos analisados para esta finalidade. Com o auxílio do Plano de Manejo da Unidade e do Diagnóstico da Unidade realizado por estudantes da Universidade de Brasília em parceria com o Laboratório de Biodiversidade e Áreas Protegidas da UnB foi possível contextualizar o estágio de implantação e de gestão que se encontra o PARNA Chapada dos Veadeiros. Dados estes que são apresentados no transcorrer deste estudo.

\section{Etapa II_ Inventário dos Atrativos e atividades do PARNA Chapada dos Veadeiros}

Nesta etapa da pesquisa foi realizado um levantamento para identificar os principais atrativos a serem aplicados ao método ROVUC. A escolha dos atrativos foi definida por meio de um pré-levantamento realizado pelos autores em parceria com os gestores do ICMBIO/PNCV. Considerando a elevada quantidade e diversidade de recursos naturais e de beleza cênica do PNCV, foram selecionados apenas os atrativos com uma perspectiva de serem implementados no horizonte de aproximadamente 15 anos. No início desta etapa, houve uma reunião de alinhamento, antes das oficinas principais, para que além de elencar os atrativos a serem trabalhados, a equipe de mediadores, composta pelos pesquisadores e gestores, pudessem compreender a metodologia de aplicação e de coleta dos dados.

Posto isso, para facilitar a aplicação do método, os atrativos foram divididos em relação à sua localização geográfica. Assim sendo, os atrativos ao sul do Pouso Alto foram validados e classificados por guias de turismo atuantes nas cidades de Alto Paraíso de Goiás, São Jorge e Colinas do Sul e os atrativos localizados ao norte do Pouso Alto foram validados e classificados pelos guias de turismo atuantes nas cidades de Cavalcante, Teresina de Goiás e Nova Roma. O convite aos guias de Turismo para a participação das oficinas de trabalho foi feito por parte da gestão do PNCV. Foram convidados os guias de Turismo com mais experiência e mais atuantes 
nestas áreas, em geral, com o perfil mais desbravador, levando em consideração que boa parte dos atrativos aqui tratados ainda não possuem ordenamento do uso público e possuem o mínimo ou nenhuma infraestrutura de acesso. As oficinas foram desenvolvidas conforme o planejamento descrito no Quadro 1.

Quadro 1: Planejamento das oficinas.

Frame 1: Workshop planning.

\begin{tabular}{|c|c|c|c|}
\hline Oficina & Localização & Data & Participantes \\
\hline $\begin{array}{c}\text { Atrativos ao Norte do } \\
\text { Pouso Alto }\end{array}$ & $\begin{array}{l}\text { Fazenda } \\
\text { Miraflores }\end{array}$ & $18 / 09 / 2018$ & $\begin{array}{c}13 \text { participantes (4 gestores, } 7 \\
\text { guias de turismo e } 02 \\
\text { pesquisadores) }\end{array}$ \\
\hline $\begin{array}{c}\text { Atrativos ao Sul do } \\
\text { Pouso Alto }\end{array}$ & $\begin{array}{l}\text { Auditório do } \\
\text { PARNA Chapada } \\
\text { dos Veadeiros }\end{array}$ & 05/10/2018 & $\begin{array}{c}11 \text { participantes (03 gestores, } \\
06 \text { guias de turismo e } 02 \\
\text { pesquisadores) }\end{array}$ \\
\hline
\end{tabular}

Após o levantamento inicial, elaborado pelos pesquisadores e gestores, os atrativos listados foram validados pelos guias de turismo, no início das oficinas de trabalho (Figura 6).
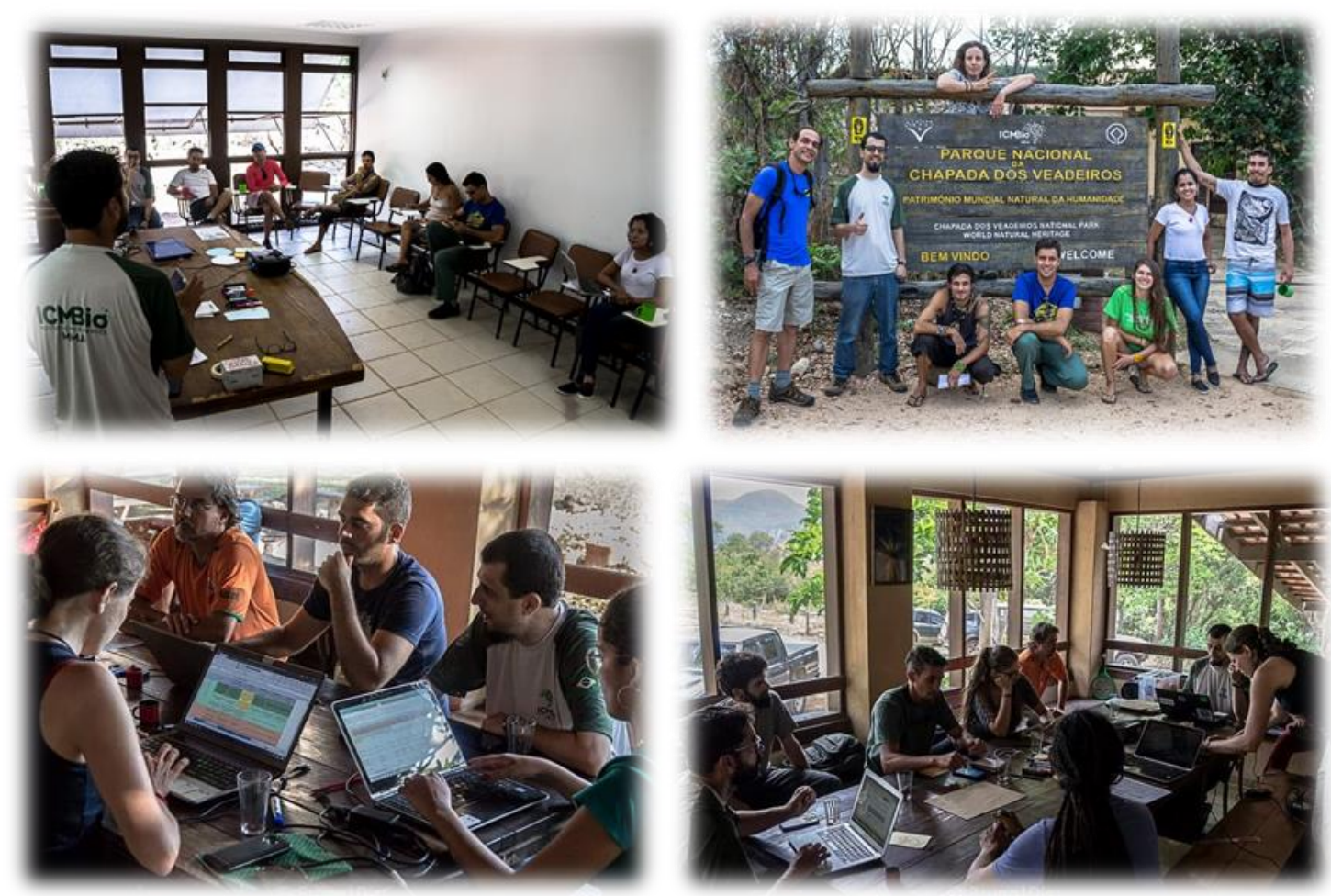

Figura 6: Oficinas de trabalho para a classificação dos atrativos do PNCV de acordo com os atritbutos do ROVUC.

Figure 6: Workshops for the classification of the attractions of the PNCV according to the attributes of ROVUC.

Fonte: Bruno Dias (2018).

Source: Bruno Dias (2018). 
Nesta etapa, os guias tiveram a oportunidade de validar os atrativos selecionados e ainda acrescentar à lista, algum outro atrativo, considerados por eles, de alta pertinência, resultando em 11 locais ou atrativos ao norte e 16 ao sul do PNCV (Quadro 2). Cabe ressaltar que os dados coletados sobre os atrativos foram obtidos a partir da participação e da experiência do grupo nas oficinas, não havendo visita in loco a estes atrativos.

Quadro 2: Listagem dos atrativos estudados.

Frame 2: List of studied attractions.

\begin{tabular}{|l|c|c|c|}
\hline \multicolumn{2}{|c|}{ Atrativos ao Norte do Pouso Alto } & \multicolumn{2}{|c|}{ Atrativos ao Sul do Pouso Alto } \\
\hline $\mathbf{1}$ & Ponte de Pedra & $\mathbf{1}$ & Sertão Zen \\
\hline $\mathbf{2}$ & Roncador & $\mathbf{2}$ & Anjos e Arcanjos \\
\hline $\mathbf{3}$ & Fiandeiras lado norte & $\mathbf{3}$ & Cânions e Cariocas \\
\hline $\mathbf{4}$ & Cruzeiro & $\mathbf{4}$ & Borrachudo Chapada Alta \\
\hline $\mathbf{5}$ & Cozido & $\mathbf{5}$ & Macacos \\
\hline $\mathbf{6}$ & Montes Claros & $\mathbf{6}$ & Jardim de Maytrea \\
\hline $\mathbf{7}$ & Maria Teles & $\mathbf{7}$ & Morro da Baleia e Bailarina \\
\hline $\mathbf{8}$ & Novo Mundo & $\mathbf{8}$ & Buracão \\
\hline $\mathbf{9}$ & Santana & $\mathbf{9}$ & Travessia das Sete Quedas \\
\hline $\mathbf{1 0}$ & Colemar & $\mathbf{1 0}$ & Saltos e Carrossel \\
\hline $\mathbf{1 1}$ & Caminho dos Veadeiros. & $\mathbf{1 1}$ & Simão Correia \\
\hline- & - & $\mathbf{1 2}$ & Abismo e Janela \\
\hline- & - & $\mathbf{1 3}$ & Fiandeiras lado sul \\
\hline- & - & $\mathbf{1 4}$ & Cachoeira do Dragão \\
\hline- & - & $\mathbf{1 5}$ & Barroco \\
\hline- & - & $\mathbf{1 6}$ & Rio Pretinho e Magic Canion \\
\hline
\end{tabular}

Etapa III_ Oficinas para a caracterização das atividades atuais e potenciais e
para classificação dos atrativos ou áreas de visitação

Após a consolidação da escolha dos atrativos a serem trabalhados em cada uma das regiões do PNCV (norte e sul), os participantes das oficinas foram convidados a listar todas as atividades existentes (atuais) e, seguindo sua experiência, aquelas com potencial de serem desenvolvidas em cada um dos locais, denominados aqui, atrativos (Quadros 4 e 5 , adiante). Na sequência, os participantes foram conduzidos a classificar cada atrativo de acordo com os atributos, adaptados do ROVUC (ICMBio, 2018). Além dos atributos propostos pelo ROVUC (Figura 7), foram acrescentados seis: (i) alvos prioritários para a conservação; (ii) dificuldade de acesso; aceitabilidade de impactos ambientais negativos (iii) grau, e (iv) prevalência; e aceitabilidade de impactos sociais negativos (v) grau, e (vi) prevalência (Quadros 7 e 8, adiante). 


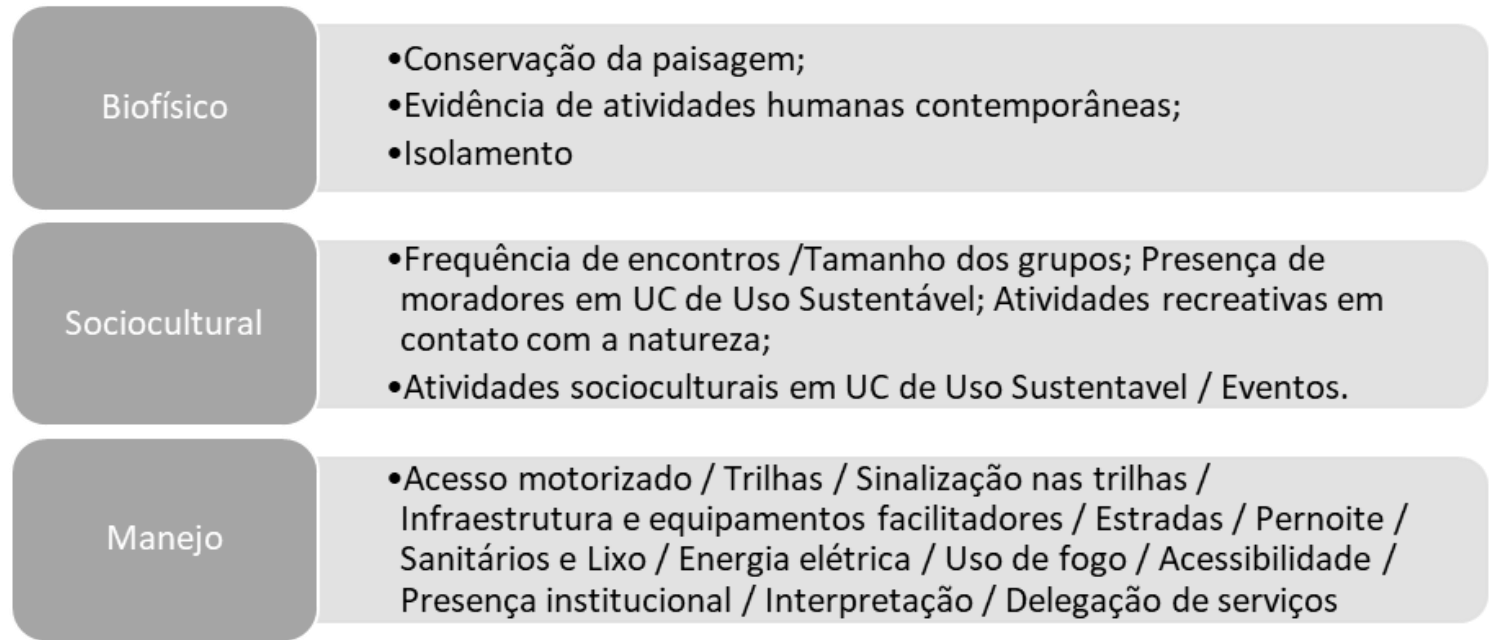

Figura 7: Atributos do Rol de Oportunidades de Visitação em Unidades de Conservação - ROVUC.

Figure 7: Attributes of the Recreation Opportunity Spectrum - ROVUC.

Fonte: Rol de Oportunidades de Visitação em Unidades de Conservação - ROVUC (ICMBio, 2018).

Source: Recreation Opportunity Spectrum in Conservation Units - ROVUC (ICMBio, 2018).

As classes de experiências foram apresentadas aos participantes conforme o Quadro 3, representando um gradiente de experiências que varia de uma visitação a locais com a máxima naturalidade, mínima intervenção humana e baixa presença de visitantes (Prístina) até uma situação de mínima naturalidade, máxima intervenção humana e grande presença de visitantes (Ruralizada):

Quadro 3: Classes de experiências do Rol de Oportunidades de Visitação em Unidades de Conservação - ROVUC.

Frame 3: Classes of experiences of: List of Visiting Opportunities in Protected Areas - ROVUC

\begin{tabular}{|c|c|c|}
\hline $\begin{array}{l}\text { CLASSES DE } \\
\text { EXPERIÊNCIA }\end{array}$ & DESCRIÇÃO & $\begin{array}{c}\text { GRAU DE } \\
\text { INTERVENÇÃO } \\
\text { NOS } \\
\text { ATRIBUTOS }\end{array}$ \\
\hline Prístina & $\begin{array}{l}\text { Experiência de visitação que envolve aventura, isolamento, } \\
\text { desafio, autonomia em ambientes naturais e uma interação } \\
\text { intensa com a natureza. }\end{array}$ & $\begin{array}{l}\text { baixo grau de } \\
\text { intervenção }\end{array}$ \\
\hline Natural & $\begin{array}{l}\text { Ainda permite algum nível de isolamento, aventura e } \\
\text { independência nos ambientes naturais, ao mesmo tempo que } \\
\text { oferece a possibilidade de segurança e conforto. }\end{array}$ & $\begin{array}{l}\text { médio grau de } \\
\text { intervenção }\end{array}$ \\
\hline Seminatural & $\begin{array}{l}\text { Possibilita grande interação entre grupos de pessoas (famílias, } \\
\text { amigos...) em ambientes naturais, com a possibilidade de } \\
\text { tranquilidade, segurança, conforto e comodidade. }\end{array}$ & \multirow{3}{*}{$\begin{array}{l}\text { alto grau de } \\
\text { intervençãa }\end{array}$} \\
\hline Ruralizada & $\begin{array}{l}\text { Possibilita o contato com moradores e seu modo de vida local, } \\
\text { tranquilidade, segurança, conforto e comodidade. }\end{array}$ & \\
\hline Urbanizada & $\begin{array}{l}\text { Em ambientes com menos naturalidade, que possibilita a interação } \\
\text { com os moradores locais, proporcionando conforto e praticidade. }\end{array}$ & \\
\hline
\end{tabular}

Fonte: Rol de Oportunidades de Visitação em Unidades de Conservação - ROVUC (ICMBio, 2018).

Source: List of Visiting Opportunities in Protected Areas - ROVUC (ICMBio, 2018).

O grupo classificou cada atributo de cada atrativo de acordo com a percepção construída coletivamente a partir dos critérios apresentados. Houve consenso em todas as categorizações (Quadros 7 e 8, adiante). 


\section{Resultados}

\section{Potencial de Uso Público da UC}

A visitação é uma das atividades de uso público de maior relevância prevista no Plano de Manejo do PNCV, e vem crescendo constantemente (Gráfico 1). Até 2013 a visitação era condicionada à contratação de um guia de turismo, no entanto, com a Instrução Normativa 08/2008, o ICMBIO tornou facultativa a presença do guia de turismo, oportunizando aos visitantes a escolha de contratar ou não um guia/condutor. Esta nova conduta é um dos fatores que pode explicar o aumento do número de visitantes, assim como, o asfaltamento da rodovia que dá acesso a entrada do parque, no ano de 2014.

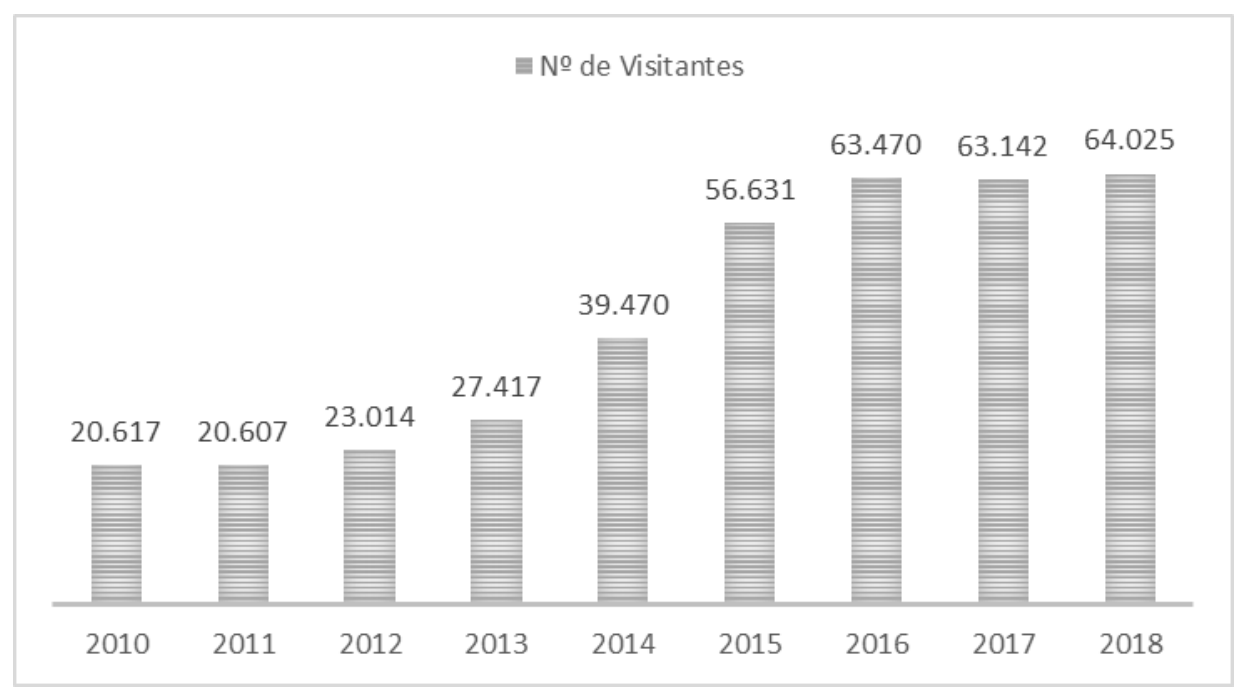

Gráfico 1: Fluxo de visitação no período de 2010 a 2018.

Graph 1: Visiting flow from 2010 to 2018.

Fonte: Gestão do PARNA Chapada dos Veadeiros (2018). Source: PARNA Management Chapada dos Veadeiros (2018).

O Plano de Manejo em vigência é relativo a área anterior do PNCV, antes da ampliação de 2017, e prevê mais de uma dezena de atrativos a serem disponibilizados à visitação. No entanto, devido a recursos limitados, nem todos foram implementados. Atualmente, cinco atrativos estão abertos à visitação, são eles: "Saltos e Corredeiras", "Cânions e Cariocas", "Trilha da Seriema", "Travessia das Sete Quedas" (único atrativo que oferece pernoite) e o mais recente inaugurado, a "Trilha do Carrossel".

A trilha dos "Saltos e Corredeiras" tem a extensão de $11 \mathrm{~km}$ (ida e volta) de caminho linear. Variando entre dificuldade moderada a pesada, o atrativo é sinalizado por setas pintadas em cor amarela e possui a capacidade de suporte estimada em 250 pessoas por dia. "O percurso é feito na maior parte do tempo em terreno acidentado e bastante pedregoso [...] inclui a passagem pelo Garimpo, considerado o maior garimpo de cristal de quartzo da região quando estava em atividade (1912 a 1961)" (ALVES; ANDRADE 2017).

Com extensão de $12 \mathrm{~km}$, a trilha dos "Canions e Cariocas" é sinalizada por setas em cor vermelha, possui características de dificuldade moderada e tem a 
capacidade de suporte de 200 pessoas por dia. Normalmente, em períodos chuvosos, por colocar em risco a segurança dos visitantes, o trajeto por dentro dos cânions é interditado devido ao grande volume de água, embora as trilhas de acesso e banho, em alguns pontos, continuem liberados.

A "trilha da Seriema" é a menor trilha, com $850 \mathrm{~m}$ de distância, a trilha pode ser percorrida em aproximadamente 30 minutos e possui um nível de dificuldade leve, devido ao espaço limitado, sua capacidade de suporte é estimada em até 300 pessoas por dia. (ICMBio, 2009).

A "Travessia das Sete Quedas" possui a extensão de $23 \mathrm{~km}$, com opção de pernoite por até duas noites na área destinada para camping. Esta trilha de longo curso atravessa áreas extremamente conservadas, ao longo do Rio Preto, e fica aberta ao público por todo o período de seca, normalmente compreendidos pelos meses de maio a outubro.

Além dos atrativos mencionados acima, o Plano de Manejo elaborado em 2009 previa outros 16 atrativos, desses, apenas 01 foi implementado, a "Trilha do Carrossel", recentemente aberta ao público, em 2018. Dos 15 outros atrativos previstos no Plano de Manejo e não implementados, seis estão contemplados neste estudo, auxiliando assim, a tomada de decisão futura para priorização de ações de planejamento. Com base na recente ampliação do PNCV, a equipe gestora, elaborou um novo plano de manejo, contemplando inclusive a área nova, mas este ainda não foi publicado, e o Plano de Uso Público, complementar ao Plano de Manejo, ainda será elaborado posteriormente. Nesse sentido, o presente trabalho visa contribuir para este planejamento futuro

Para além da relevância ecológica, o PARNA Chapada dos Veadeiros é um dos parques mais visitados do país. Na última década, recebeu quase meio milhão de visitantes (Gráfico 1), com fluxo de visitas concentrado nos meses de julho e janeiro , coincidindo com a alta temporada brasileira. Os 11 Parques Nacionais do Cerrado receberam cerca de 800 mil visitantes em 2018, contando com 51 atividades distintas entre aquáticas, de altura, de contemplação, com veículos, e de trilhas (ICMBio, 2020)

No Parque Nacional da Chapada dos Veadeiros existem 05 atividades inventariadas, contempladas nos atrativos abertos para visitação, de acordo com os documentos consultados e o site da instituição (ICMBio, 2020). São elas: banhos; caminhada, caminhada de longo curso, visita para fins educacionais; e observação de fauna.

\section{Inventário dos atrativos e atividades existentes e potenciais}

A diversidade e a quantidade de atividades atuais e potenciais identificadas pelos participantes para os atrativos trabalhados nas oficinas (Quadros 2, 4, e 5) foi bem maior do que as identificadas até então nos documentos analisados para os cinco atrativos abertos para visitação. Nos 16 atrativos da região sul do PNCV, nem todos com visitação ordenada, foram identificadas 66 atividades, das quais ao menos 43 já são realizadas em algum atrativo além de outras que podem potencialmente ser realizadas em diversos atrativos (Quadro 5). Para os atrativos ao norte do Pouso Alto, ao menos 40 atividades foram identificadas, das quais 13 já acontecem atualmente (Quadro 4). 
Quadro 4: Inventário das atividades existentes, ou atuais $(A)$ e das atividades potenciais $(P)$ dos atrativos do Parque Nacional da Chapada dos Veadeiros, ao norte do Pouso Alto, realizado em oficina com guias e gestores locais. (A/P foram identificadas como atividades atuais extremamente incipientes).

Frame 4: Inventory of existing or current activities $(A)$ and potential activities $(P)$ of the attractions of the Chapada dos Veadeiros National Park, north of Pouso Alto, carried out in a workshop with local guides and managers. (A / $\mathrm{P}$ have been identified as extremely incipient current activities).

\begin{tabular}{|c|c|c|c|c|c|c|c|c|c|c|c|}
\hline Atividades & 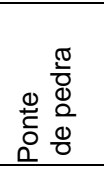 & 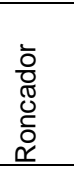 & 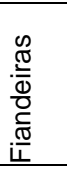 & 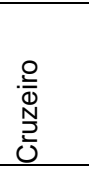 & $\begin{array}{l}\stackrel{\circ}{\bar{N}} \\
0 \\
0 \\
\end{array}$ & 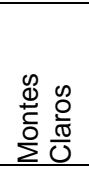 & 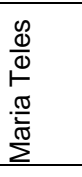 & $\begin{array}{l}0 \\
0 \\
0 \\
\sum \\
\sum \\
0 \\
0 \\
0 \\
z\end{array}$ & 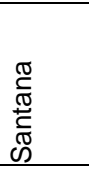 & $\begin{array}{l}\overline{\bar{\varpi}} \\
\bar{\Xi} \\
0 \\
\end{array}$ & 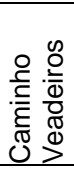 \\
\hline Análise de sítio / Exploratório & & & A & & A & A & A & & $P$ & & $A$ \\
\hline Abertura do Portão Norte & & & & & & & & & $P$ & & \\
\hline Banho & A & A & & & A & $A / P$ & $A / P$ & $\mathrm{~A} / \mathrm{P}$ & $\mathrm{A} / \mathrm{P}$ & $A / P$ & $A$ \\
\hline Bike & $P$ & & & & A & & & & & & \\
\hline Birdwhatching & A & & & & $P$ & $P$ & & & $P$ & & \\
\hline Boiacross & & & & & & $P$ & & & $P$ & & \\
\hline Bungy Jump & $P$ & & $P$ & & & & & & & & \\
\hline Cachoeirismo & & & & & & & $P$ & $P$ & $P$ & & \\
\hline Caminhada & & A & $P$ & & A & $P$ & $P$ & $P$ & & A & $A$ \\
\hline Caminhada de montanha & & $P$ & $P$ & & & & $P$ & & & & \\
\hline Camping & $P$ & $P$ & $P$ & $P$ & $P$ & $P$ & $P$ & & $P$ & $P$ & $A$ \\
\hline Canionismo & A & & & & $P$ & $P$ & $P$ & & $P$ & $P$ & \\
\hline Contemplação & A & & & $P$ & $P$ & $P$ & $P$ & $P$ & A & $P$ & $A$ \\
\hline Escalada & $P$ & $P$ & $P$ & & $P$ & & $P$ & & & & \\
\hline Esquibunda & & & & & & $P$ & & & & & \\
\hline Expedições & & & & & $A$ & A & A & & A & & $A$ \\
\hline Fotografia & $P$ & & & & & $P$ & $P$ & & & $P$ & $P$ \\
\hline Mirante & & $P$ & $P$ & & & & & & & A & \\
\hline Nascer/Pôr do sol & $P$ & & & & & & & & & & \\
\hline \multicolumn{12}{|l|}{ Natação } \\
\hline Observação de astros & $P$ & & & $\mathrm{P}$ & $P$ & & & & $P$ & $P$ & $P$ \\
\hline Observação de fauna e flora & A & $P$ & & $A / P$ & $P$ & $P$ & & & $P$ & $A / P$ & $P$ \\
\hline Pendulo & $P$ & & $\mathrm{P}$ & & $P$ & & & & & & \\
\hline Pernoite & & & & & A & & & & & $P$ & $P$ \\
\hline Pesquisa / Atv. Educativa & A & & $P$ & $A / P$ & & A & & & $A / P$ & $A / P$ & $P$ \\
\hline Rafting & & & & & & & & & $\mathrm{P}$ & & \\
\hline Rapel & $P$ & & $P$ & & $P$ & $P$ & $P$ & $P$ & $P$ & & \\
\hline Swing Jump & $P$ & & & & $P$ & & & & & & \\
\hline Tirolesa & $P$ & $P$ & & & & & & & & & \\
\hline Travessia & & & $P$ & $P$ & $P$ & & & & $P$ & $P$ & $P$ \\
\hline Trekking & A & A & $P$ & $A / P$ & $P$ & $A / P$ & $P$ & $P$ & $\mathrm{~A} / \mathrm{P}$ & $A / P$ & $P$ \\
\hline Trilha com acessibilidade & & & & & & & & & $P$ & & \\
\hline Trilha familiar & & & & & & & & & $P$ & & \\
\hline Trilha noturna & $P$ & & & & & & & & & & \\
\hline
\end{tabular}

Continua... 
...continuação.

\begin{tabular}{|c|c|c|c|c|c|c|c|c|c|c|c|}
\hline Atividades & 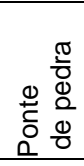 & 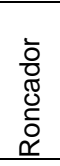 & $\begin{array}{l}\frac{\pi}{\pi} \\
\frac{\pi}{0} \\
\frac{0}{0} \\
\frac{\pi}{4} \\
\frac{\pi}{1}\end{array}$ & $\begin{array}{l}\stackrel{ }{\frac{N}{N}} \\
\stackrel{2}{N} \\
\text { U }\end{array}$ & $\begin{array}{l}\frac{0}{\mathrm{O}} \\
\mathrm{N} \\
0\end{array}$ & 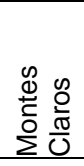 & 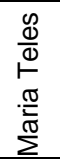 & 号 $\frac{0}{0}$ & 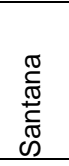 & $\begin{array}{l}\frac{\bar{\sigma}}{\tilde{E}} \\
\overline{0}\end{array}$ & 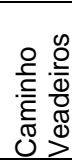 \\
\hline Trilhas interpretativas & & & & & & & & & & & $P$ \\
\hline Turismo gastronômico & & & & & & & & & & $\mathrm{P}$ & \\
\hline Turismo histórico & & & & $A / P$ & & & & & $\mathrm{P}$ & $\mathrm{P}$ & \\
\hline Turismo rural & & & & & & & & & & $\mathrm{P}$ & $\mathrm{P}$ \\
\hline Voo de balão & & & & $\mathrm{P}$ & & & & & & & \\
\hline Voo duplo / Pouso & & & & $P$ & $P$ & $P$ & $\mathrm{P}$ & & & & $\mathrm{P}$ \\
\hline
\end{tabular}

Quadro 5: Inventário das atividades existentes, ou atuais $(A)$ e das atividades potenciais $(P)$ dos atrativos do Parque Nacional da Chapada dos Veadeiros, ao sul do Pouso Alto, realizado em oficina com guias e gestores locais. (A/P foram identificadas como atividades atuais extremamente incipientes).

Frame 5: Inventory of existing or current activities $(A)$ and potential activities $(P)$ of the attractions of the Chapada dos Veadeiros National Park, south of Pouso Alto, carried out in a workshop with guides and local managers. (A / P have been identified as extremely incipient current activities).

\begin{tabular}{|c|c|c|c|c|c|c|c|c|c|c|c|c|c|c|c|c|}
\hline Atividades & 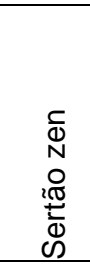 & 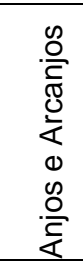 & 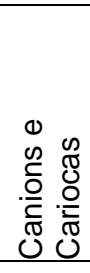 & 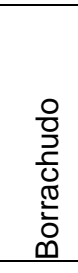 & 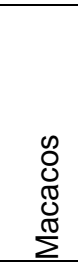 & 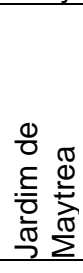 & 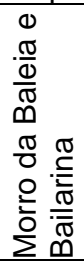 & 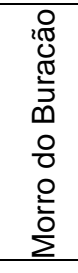 & 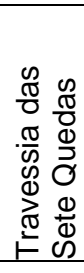 & 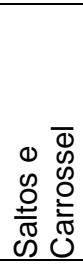 & 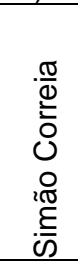 & 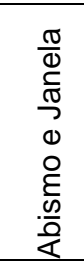 & 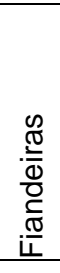 & 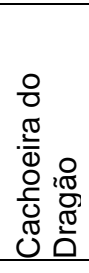 & $\begin{array}{l}\text { O } \\
\text { O } \\
\frac{0}{\pi} \\
\infty\end{array}$ & 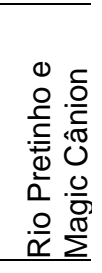 \\
\hline Acessibilidade & & & & & & $\mathrm{P}$ & & & & $A$ & & & & & & \\
\hline Agroturismo & & $\mathrm{P}$ & & & & & $\mathrm{P}$ & & & & & & & & & \\
\hline Alimentação & & & & $A$ & & & & & & & $A$ & & & & & \\
\hline Atrativo kids & & & & & & & & & & & & & & & $\mathrm{P}$ & \\
\hline Balneário & & $A$ & & & & & & & & A & & & & & & \\
\hline Banho & $A$ & $A$ & $\mathrm{~A} / \mathrm{P}$ & $A$ & $\mathrm{~A} / \mathrm{P}$ & & $\mathrm{A} / \mathrm{P}$ & & $A$ & $A$ & $A$ & $A$ & & A & $A$ & A \\
\hline Base jump & & & & & & & $P$ & $\mathrm{P}$ & & $\mathrm{P}$ & $\mathrm{P}$ & $\mathrm{P}$ & $\mathrm{P}$ & & & \\
\hline Bike & $\mathrm{P}$ & & & & $\mathrm{P}$ & $\mathrm{P}$ & & & $\mathrm{P}$ & $\mathrm{P}$ & $\mathrm{P}$ & & & & $\mathrm{P}$ & $\mathrm{P}$ \\
\hline Birdwhatching & $\mathrm{P}$ & $\mathrm{P}$ & $\mathrm{P}$ & $\mathrm{P}$ & $\mathrm{P}$ & & $\mathrm{P}$ & $\mathrm{P}$ & & $\mathrm{P}$ & & & & & $\mathrm{P}$ & \\
\hline Bivaque & & & & & & $\mathrm{P}$ & & & & & & & & & & \\
\hline Bote navegação & & & & & & & $\mathrm{P}$ & $\mathrm{P}$ & & & $\mathrm{P}$ & $\mathrm{P}$ & & $A$ & & \\
\hline Caminhada & $A$ & $A$ & $A$ & $A$ & $A$ & $A$ & $A$ & $\mathrm{P}$ & $A$ & A & $\mathrm{A} / \mathrm{P}$ & $\mathrm{A} / \mathrm{P}$ & $A$ & $A$ & $A$ & \\
\hline Caminhada de montanha & & $P$ & & & & & & $\mathrm{~A} / \mathrm{P}$ & & & $\mathrm{P}$ & & & & $P$ & A \\
\hline Camping & $\mathrm{A} / \mathrm{P}$ & $\mathrm{A} / \mathrm{P}$ & & $\mathrm{A} / \mathrm{P}$ & $A / P$ & & $A / P$ & $A / P$ & $A$ & $\mathrm{P}$ & $P$ & $\mathrm{P}$ & & $\mathrm{A} / \mathrm{P}$ & $\mathrm{A} / \mathrm{P}$ & $\mathrm{A} / \mathrm{P}$ \\
\hline Canionismo & & & & A & $A$ & & & & & $A$ & $\mathrm{~A} / \mathrm{P}$ & & & A & A & A \\
\hline Cavalgada & $A$ & $\mathrm{~A} / \mathrm{P}$ & & $A$ & $\mathrm{P}$ & & $\mathrm{P}$ & & & & $A$ & & & & & \\
\hline Cerimonias & $A$ & & & & & & $A$ & & $\mathrm{P}$ & & & & & & & \\
\hline Chalés & & & & $A$ & & & & & & & & & & & & \\
\hline Cicloturismo & & & & & $A$ & $\mathrm{P}$ & & & & $\mathrm{P}$ & & & & & & \\
\hline Contemplação & $A$ & $A$ & $A$ & & $A$ & A & $A$ & $\mathrm{~A} / \mathrm{P}$ & & $A$ & & $A$ & & & & \\
\hline Corrida de aventura & $A / P$ & & & & A & & & $\mathrm{P}$ & $A$ & $A$ & & & & & & \\
\hline Ecovila & & & & & & & & & & & & & & & & $A$ \\
\hline Escalada & $\mathrm{A} / \mathrm{P}$ & $\mathrm{P}$ & $\mathrm{P}$ & & $A$ & & $A$ & $\mathrm{P}$ & & $A$ & $\mathrm{P}$ & $\mathrm{P}$ & & & $\mathrm{A} / \mathrm{P}$ & $\mathrm{A} / \mathrm{P}$ \\
\hline Flutuação & & & $\mathrm{P}$ & & & & & & $A$ & $\mathrm{P}$ & & & & $\mathrm{A} / \mathrm{P}$ & & \\
\hline Fotografia & & & A/P & & & A & $A$ & A/P & $\mathrm{P}$ & $\mathrm{A} / \mathrm{P}$ & & $A$ & $A$ & $\begin{array}{l}\text { A } \\
\text { Con }\end{array}$ & tinua & \\
\hline
\end{tabular}




\begin{tabular}{|c|c|c|c|c|c|c|c|c|c|c|c|c|c|c|c|c|}
\hline Atividades & 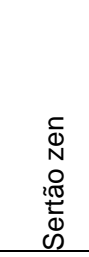 & 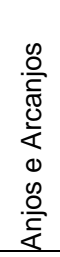 & 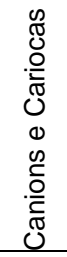 & 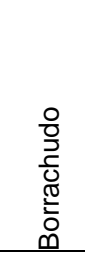 & 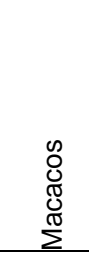 & 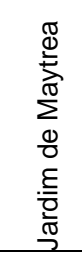 & 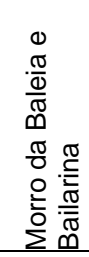 & 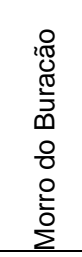 & 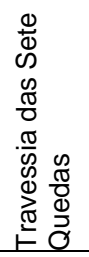 & 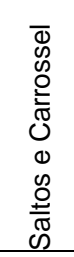 & 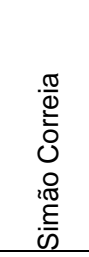 & $\begin{array}{l}\frac{\pi}{0} \\
\frac{0}{\pi} \\
\vec{T} \\
0 \\
0 \\
0 \\
\frac{0}{0} \\
\frac{-0}{0} \\
\end{array}$ & 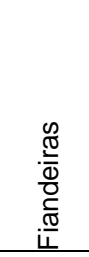 & 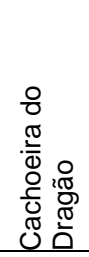 & 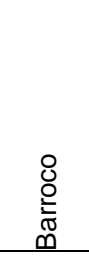 & 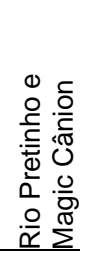 \\
\hline Geoturismo & & & & & & $P$ & $\mathrm{P}$ & $P$ & $\mathrm{P}$ & $P$ & $\mathrm{~A} / \mathrm{P}$ & & $A / P$ & & $P$ & \\
\hline Glamping & $\mathrm{P}$ & & & & & & & & & & & & & & & \\
\hline Guiamento & & & $A$ & & & & & & & $A$ & A & & & A & & \\
\hline Hi position & & & & & & $P$ & & & & & & & & & & \\
\hline Hidromassagem & & & & & & & & & & $A$ & & & & & & \\
\hline High line & & A & & & & & & & & & $P$ & $A / P$ & & & & \\
\hline Hospedagem & & & & & $P$ & & & & $P$ & $P$ & $P$ & & & $\mathrm{P}$ & & \\
\hline Infraestrutura de apoio & & & & & & $P$ & & & $P$ & $\mathrm{P}$ & & & & & & \\
\hline Jump & A & & & & A & & & & & $A / P$ & $P$ & & & & $\mathrm{P}$ & \\
\hline Meditação & A & & & & & $A$ & $\mathrm{P}$ & $A$ & & & & & & & & \\
\hline Mergulho & & & $P$ & & & & & & & & & & & $\mathrm{P}$ & & \\
\hline Mirante & $A / P$ & & & & $A / P$ & $A / P$ & $\mathrm{~A} / \mathrm{P}$ & $\mathrm{A} / \mathrm{P}$ & & $A$ & $P$ & $A / P$ & $\mathrm{~A} / \mathrm{P}$ & $A / P$ & A & \\
\hline Motocross & A & & & & & & & & & & & & & & & \\
\hline Nascer/Pôr do sol & & & & & & & $P$ & $A$ & & $\mathrm{P}$ & & $A / P$ & & & & \\
\hline Natação & & & & & & $\mathrm{P}$ & $\mathrm{P}$ & $\mathrm{P}$ & $P$ & $A / P$ & & $P$ & & A & & \\
\hline Observação de astros & & & & & $A$ & $A / P$ & $\mathrm{P}$ & $\mathrm{P}$ & A & $\mathrm{P}$ & & A & & & & \\
\hline $\begin{array}{l}\text { Observação de fauna e } \\
\text { flora }\end{array}$ & & $P$ & A & & & $A / P$ & $A / P$ & $P$ & A & $\mathrm{A} / \mathrm{P}$ & $\mathrm{P}$ & $A$ & $A / P$ & A & & \\
\hline Off road & & & & & $A / P$ & & & & & & $P$ & & & & & \\
\hline Pecuária & $A$ & & & & & & & & & & & & & & & \\
\hline Pernoite & $\mathrm{A} / \mathrm{P}$ & & & & $A / P$ & $\mathrm{P}$ & $A / P$ & $P$ & A & & A & $A / P$ & & & & \\
\hline Pesca & & & & & & & & & & & A & & & & & \\
\hline Pesquisa & & & & & $P$ & & & $P$ & $P$ & $P$ & $P$ & & $A / P$ & A & & \\
\hline Piquenique & & & $A$ & & & & & & & & & & & & & \\
\hline Psico bloc & & $P$ & A & & $A$ & & & & & & $\mathrm{P}$ & & & & & \\
\hline Psicultura & & & & & & & & & & & & & & & A & \\
\hline Rapel & $P$ & $P$ & & & & & $A / P$ & $P$ & & $\mathrm{~A} / \mathrm{P}$ & $P$ & $\mathrm{P}$ & $\mathrm{P}$ & $A$ & A & \\
\hline Saltos ornamentais & & & A & & & & & & & & & & & & & \\
\hline Slack line & A & $P$ & & & $P$ & & & & & $P$ & & $A / P$ & & & & \\
\hline Terapias/Imersão & A & & & $P$ & & & & & & & & & & & & \\
\hline Tirolesa & & & & & & & & $P$ & & $P$ & & $P$ & $\mathrm{P}$ & & & \\
\hline Travessia & $A / P$ & $P$ & & $P$ & $A / P$ & & $A / P$ & $P$ & $A$ & & $\mathrm{P}$ & & $A / P$ & $P$ & $A / P$ & $\mathrm{P}$ \\
\hline Trekking & $A / P$ & $P$ & A & $P$ & $A / P$ & & $A / P$ & A & $A$ & $A$ & $A / P$ & A & $A / P$ & $\mathrm{P}$ & & $A$ \\
\hline Trilha aquática & & & & & & & & & & $P$ & & & & & & \\
\hline Trilha noturna & & & $P$ & & $A$ & & & & & $A / P$ & $P$ & & & $A / P$ & & \\
\hline Trilha suspensa & & & & & & $P$ & & & & & & & & & & \\
\hline Tur $3^{\underline{a}}$ Idade & & $P$ & & & & $P$ & & & & & & & & & & \\
\hline Tur Cultural & & $P$ & & & & & & & & & & $P$ & & & & \\
\hline Turismo histórico & & & & & & & & & & $A$ & & $P$ & $P$ & & & \\
\hline Turismo rural & & & & & & & $\mathrm{P}$ & & & & $\mathrm{P}$ & & & & & \\
\hline Vida selvagem & & & & $\mathrm{A} / \mathrm{P}$ & $\mathrm{A} / \mathrm{P}$ & & & & $P$ & & $A / P$ & $P$ & & & & $\mathrm{P}$ \\
\hline Voo livre & & & & & & & & $\mathrm{P}$ & & & & $\mathrm{P}$ & & & & \\
\hline
\end{tabular}




\section{Caracterização e classificação dos atrativos ou áreas de visitação da UC}

A classificação dos atrativos de visitação do PNCV foi categorizada de acordo com os parâmetros propostos no roteiro metodológico para aplicação do ROVUC (ICMBio, 2018). Neste, são elencados três parâmetros biofísicos; seis socioculturais e dez relacionados ao manejo (Figura 7). No entanto, consultando as orientações originais do ROS (CLARK; STANKEY, 1979) e considerando que esta classificação proposta pelo ROVUC é um subsídio fundamental tanto para o ordenamento do uso público, mas também para o zoneamento da UC como um todo, foram acrescentados, para este trabalho, um parâmetro adicional no grupo biofísico (alvos prioritários para a conservação), um de manejo (acessibilidade) e mais quatro, dois relacionados a impactos socioambientais e dois ambientais (Quadros 7 e 8). Assim, pretendemos subsidiar com informações mais completas e mais balanceadas considerando os parâmetros de manejo, mas também os demais, particularmente os relacionados a biodiversidade, aos recursos naturais e culturais. Assim, após a explicação sobre a abordagem do ROVUC e de todo processo envolvido, foi apresentado e descrito cada parâmetro, ou atributo, e o grupo de participantes das oficinas classificou, em consenso, cada parâmetro, para cada atrativo, em uma das cinco categorias de classes de experiência (Quadros7 e 8).

Quadro 6: Legenda de apresentação dos dados do ROVUC. Frame 6: Legend for presenting ROVUC data.

\begin{tabular}{|l|l|c|}
\hline \multirow{4}{*}{\begin{tabular}{c} 
Classes de \\
\multirow{2}{*}{ Experiência }
\end{tabular}} & Prístina & P \\
\cline { 2 - 3 } & Natural & Neminatural \\
\cline { 2 - 3 } & Ruralizada & S \\
\cline { 2 - 3 } & Urbanizada & R \\
\cline { 2 - 3 } & Não se aplica & NA \\
\hline & $\begin{array}{l}\text { Dados } \\
\text { coletados }\end{array}$ não & $\mathbf{x}$ \\
\hline
\end{tabular}


Quadro 7: Classificação dos atributos dos atrativos ao sul do PNCV.

Frame 7: Classification of the attributes of the attractions to the south of the PNCV.

\begin{tabular}{|c|c|c|c|c|c|c|c|c|c|c|c|c|c|c|c|c|c|}
\hline \multirow{2}{*}{\multicolumn{2}{|c|}{ CLASSES }} & \multicolumn{16}{|c|}{ ATRATIVOS AO SUL DO POUSO ALTO } \\
\hline & & 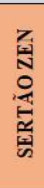 & 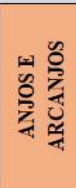 & 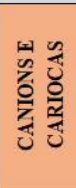 & 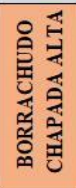 & 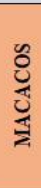 & 离 & 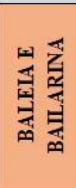 & 尊 & 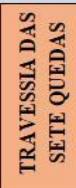 & 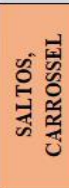 & 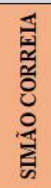 & 䨔 & 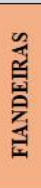 & 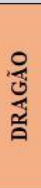 & 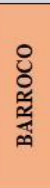 & 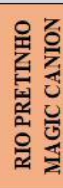 \\
\hline \multicolumn{18}{|c|}{ INDICADORES } \\
\hline \multirow{4}{*}{ \$ } & Conservação da paisagem & $\mathbf{N}$ & $\mathbf{N}$ & & $\mathbf{N}$ & $\mathbf{p}$ & & N & $\mathbf{p}$ & & & $\mathbf{N}$ & $\mathrm{N}$ & $\mathbf{p}$ & $\mathbf{p}$ & $\mathbf{R}$ & p \\
\hline & $\begin{array}{c}\text { Alvos Prioritários para Conservação (ambientes } \\
\text { sensiveis, espécies ameaçadas, espécies endêmicas) }\end{array}$ & $\mathbf{N}$ & s & & $\mathrm{N}$ & $\mathrm{N}$ & & N & N & & & $\mathrm{N}$ & N & p & $\mathrm{p}$ & N & N \\
\hline & Evidência de atividade humana contemporânea. & $\mathrm{N}$ & $\mathrm{s}$ & & $\mathbf{p}$ & $\mathbf{p}$ & & $\mathrm{N}$ & $\mathrm{p}$ & & & $\mathbf{N}$ & $\mathrm{s}$ & $p$ & P & $\mathrm{s}$ & $\mathrm{p}$ \\
\hline & $\begin{array}{l}\text { Isolamento (distância das entradas da UC e dificuldade } \\
\text { de acesso). }\end{array}$ & N & p & & $\mathbf{p}$ & $\mathbf{p}$ & & $\mathbf{N}$ & s & & & p & $\mathrm{s}$ & p & $\mathbf{P}$ & N & $\mathrm{N}$ \\
\hline \multirow{6}{*}{$5^{\circ}$} & \begin{tabular}{|c|} 
Frequência de encontros \\
Tamanho dos grupos \\
\end{tabular} & $\mathrm{N}$ & $s$ & & $P$ & $\mathbf{p}$ & & $\mathrm{N}$ & $\mathrm{N}$ & & & $\mathrm{p}$ & $s$ & $\mathbf{P}$ & $\mathrm{P}$ & $\mathbf{P}$ & $\mathrm{P}$ \\
\hline & \begin{tabular}{|l|}
\multicolumn{2}{|c|}{ Tamanho dos grupos } \\
Presenca de moradores em Unidades de Conservacão
\end{tabular} & $\mathrm{N}$ & $s$ & & & $\mathbf{N}$ & & $\mathbf{N}$ & $\mathbf{N}$ & & & $\mathbf{N}$ & $\mathrm{s}$ & $\mathbf{P}$ & $\mathbf{N}$ & $\mathbf{P}$ & $\mathbf{P}$ \\
\hline & $\begin{array}{l}\text { Presença de moradores em Unidades de Conservação } \\
\text { de Uso Sustentável }\end{array}$ & $\mathbf{p}$ & N & & $\mathbf{p}$ & $\mathbf{p}$ & & $\mathbf{p}$ & $\mathbf{N}$ & & & p & $\mathbf{N}$ & p & $\mathbf{p}$ & p & p \\
\hline & $\begin{array}{l}\text { Atividades recreativas e em contato com a natureza e } \\
\text { turismo ecologico }\end{array}$ & N & $\mathbf{N}$ & & p & P & & $\mathbf{p}$ & $\mathbf{p}$ & & & p & N & p & p & p & p \\
\hline & $\begin{array}{l}\text { Atividades socioculturais em unidades de conservação } \\
\text { de Uso Sustentável }\end{array}$ & NA & $\mathbf{P}$ & & $\mathbf{p}$ & $\mathbf{p}$ & & $\mathbf{P}$ & & & & P & $\mathbf{p}$ & $\mathbf{p}$ & p & $\mathbf{p}$ & $\mathbf{p}$ \\
\hline & $\begin{array}{c}\text { Eventos } \\
\end{array}$ & $\mathbf{p}$ & $\mathbf{p}$ & & $\mathbf{p}$ & $\mathbf{p}$ & & $\mathbf{P}$ & $\mathbf{P}$ & & & $\mathbf{p}$ & $\mathbf{p}$ & $\mathbf{p}$ & $\mathbf{p}$ & $\mathbf{p}$ & $\mathbf{p}$ \\
\hline \multirow{10}{*}{$5^{50}$} & Acesso Motorizado & $\mathrm{N}$ & $\mathbf{p}$ & & $\mathbf{p}$ & $\mathbf{p}$ & & $\mathbf{P}$ & $\mathrm{p}$ & & & $\mathbf{P}$ & $\mathbf{P}$ & $\mathbf{p}$ & $\mathbf{P}$ & $\mathrm{N}$ & $\mathbf{P}$ \\
\hline & Dificuldade de acesso & $\mathbf{P}$ & $\mathbf{P}$ & & $\mathbf{P}$ & $\mathbf{P}$ & & $\mathbf{P}$ & $\mathrm{s}$ & & & $\mathbf{P}$ & $\mathbf{P}$ & $\mathbf{P}$ & $\mathbf{P}$ & $\mathbf{P}$ & $\mathbf{P}$ \\
\hline & Estradas & $\mathbf{P}$ & $\mathbf{P}$ & & $\mathbf{P}$ & $\mathbf{p}$ & & $\mathbf{p}$ & $\mathrm{s}$ & & & $\mathbf{p}$ & $\mathbf{P}$ & $\mathbf{P}$ & $\mathbf{p}$ & $\mathrm{N}$ & $\mathbf{p}$ \\
\hline & $\begin{array}{c}\text { Trilhas } \\
\end{array}$ & $\mathbf{p}$ & $\mathbf{p}$ & & $\mathbf{P}$ & $\mathbf{p}$ & & $\mathbf{P}$ & $P$ & & & $\mathbf{P}$ & $\mathbf{p}$ & $\mathbf{P}$ & $\mathbf{P}$ & $\mathbf{P}$ & $P$ \\
\hline & Sinalização e Interpretação nas Trilhas & $\mathbf{P}$ & p & & $\mathbf{P}$ & $p$ & & $\mathbf{P}$ & $\mathbf{p}$ & & & $\mathbf{p}$ & $\mathbf{P}$ & $\mathbf{P}$ & $\mathbf{p}$ & $\mathbf{P}$ & $\mathbf{P}$ \\
\hline & Edificaçôes e equipamentos facilitadores & $\mathrm{P}$ & $\mathbf{p}$ & & $\mathbf{P}$ & $\mathrm{p}$ & & $\mathbf{p}$ & $\mathrm{P}$ & & & $\mathbf{p}$ & $\mathbf{p}$ & $\mathbf{p}$ & $\mathrm{N}$ & $\mathbf{P}$ & $\mathbf{P}$ \\
\hline & $\begin{array}{l}\text { Pernoite } \\
\end{array}$ & $\mathbf{P}$ & $\mathbf{N}$ & & $\mathbf{N}$ & $\mathbf{P}$ & & $\mathbf{P}$ & $\mathbf{P}$ & & & $\mathbf{p}$ & $\mathbf{P}$ & $\mathbf{P}$ & $\mathrm{N}$ & $\mathbf{P}$ & $\mathbf{P}$ \\
\hline & Sanitários e lixo. & $p$ & $p$ & & $\mathrm{~N}$ & $p$ & & $p$ & $p$ & & & $\mathbf{p}$ & $p$ & $p$ & $\mathbf{N}$ & $\mathbf{p}$ & $\mathrm{p}$ \\
\hline & $\begin{array}{c}\text { Acessibilidade } \\
\text { Presenca Institucional }\end{array}$ & $\mathbf{p}$ & $p$ & & $\mathbf{p}$ & $\mathbf{p}$ & & $\mathbf{p}$ & $\mathbf{p}$ & & & $\mathbf{p}$ & $\mathbf{p}$ & $\mathbf{p}$ & $\mathbf{p}$ & $\mathbf{p}$ & $\mathbf{P}$ \\
\hline & $\begin{array}{l}\text { Presença Institucional } \\
\text { Delegação de serviços }\end{array}$ & $\mathbf{P}$ & $\mathbf{P}$ & & $\mathbf{P}$ & $\mathbf{P}$ & & $\mathbf{P}$ & $\mathbf{P}$ & & & $\mathbf{P}$ & $\mathbf{p}$ & $\mathrm{N}$ & $\mathbf{p}$ & $\mathbf{P}$ & $\mathbf{p}$ \\
\hline \multirow{3}{*}{\begin{tabular}{|c|} 
ACEITABILI \\
DADE DOS \\
IMPACTOS \\
AMBIENTAI \\
S \\
NEGATIVOS
\end{tabular}} & & & & & & & & & & & & & & & & & \\
\hline & a-Grau do impacto & s & $\mathbf{N}$ & & $\mathbf{p}$ & p & & $\mathrm{s}$ & N & & & $\mathrm{N}$ & $\mathrm{s}$ & $\mathrm{p}$ & $\mathbf{p}$ & $\mathrm{R}$ & p \\
\hline & b-Prevalência do impacto & $\mathbf{N}$ & $\mathrm{N}$ & & $\mathbf{P}$ & $\mathbf{p}$ & & $\mathrm{s}$ & $\mathbf{N}$ & & & $\mathrm{N}$ & $\mathrm{N}$ & p & $\mathbf{p}$ & $\mathrm{R}$ & $\mathrm{p}$ \\
\hline \multirow{2}{*}{\begin{tabular}{|} 
ACEITABILI \\
DADE DOS \\
IMPACTOS \\
SOCIAIS \\
NEGATIVOS
\end{tabular}} & a-Grau do impacto & $\mathbf{N}$ & $\mathbf{p}$ & & $\mathbf{p}$ & p & & $\mathrm{s}$ & p & & & $\mathbf{P}$ & N & $\mathbf{p}$ & P & $\mathrm{s}$ & $\mathrm{p}$ \\
\hline & b- Prevalência do impacto & $\mathrm{s}$ & p & & $\mathbf{p}$ & $\mathbf{p}$ & & N & p & & & $\mathbf{p}$ & N & p & $\mathbf{p}$ & $\mathbf{N}$ & p \\
\hline
\end{tabular}


Quadro 8: Classificação atributos dos atrativos ao norte do PNCV.

Table 8: Attribute classification of attractions north of the PNCV.

\begin{tabular}{|c|c|c|c|c|c|c|c|c|c|c|c|c|}
\hline \multirow{2}{*}{\multicolumn{2}{|c|}{ CLASSES }} & \multicolumn{11}{|c|}{ ATRATIVOS AO NORTE DO POUSO ALTO } \\
\hline & & 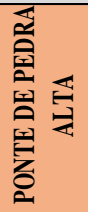 & 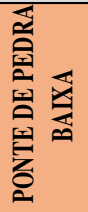 & 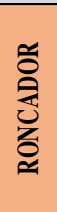 & $\begin{array}{l}\text { 을 } \\
\text { 종 } \\
\text { 즌 }\end{array}$ & 令 & 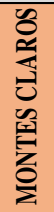 & 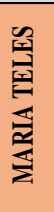 & 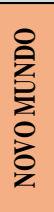 & 恴 & 㚆 & 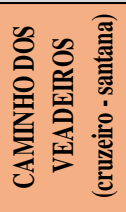 \\
\hline \multirow[t]{5}{*}{ ATRIBUTOS } & \multicolumn{12}{|l|}{ INDICADORES } \\
\hline & Conservação da paisagem & $\mathbf{P}$ & $\mathbf{x}$ & $\mathbf{N}$ & $\mathbf{P}$ & $\mathbf{N}$ & $\mathbf{N}$ & $\mathbf{N}$ & $\mathbf{P}$ & $\mathbf{s}$ & $\mathbf{s}$ & $\mathbf{P}$ \\
\hline & $\begin{array}{c}\text { Alvos Prioritários para Conservação (ambientes } \\
\text { sensíveis, es pécies ameaçadas, espécies endêmicas) }\end{array}$ & N & $\mathrm{x}$ & $N$ & $\mathbf{P}$ & $\mathbf{P}$ & $N$ & N & $N$ & s & $P$ & $\mathbf{P}$ \\
\hline & Evidência de atividade humana contemporâne a. & $\mathbf{P}$ & $\mathbf{x}$ & $\mathbf{N}$ & $\mathbf{P}$ & $\mathbf{N}$ & $\mathbf{N}$ & $\mathbf{N}$ & $\mathbf{N}$ & $\mathbf{N}$ & $\mathbf{N}$ & $\mathbf{N}$ \\
\hline & $\begin{array}{l}\text { Isolamento (distância das entradas da UC e dificuldade } \\
\text { de acesso). }\end{array}$ & $\mathbf{P}$ & $\mathbf{x}$ & $\bar{P}$ & $\mathrm{~s}$ & $\bar{P}$ & $\bar{P}$ & $\bar{P}$ & $N$ & $N$ & $N$ & $\mathbf{N}$ \\
\hline \multirow{6}{*}{ so } & $\begin{array}{c}\text { Frequência de encontros } \\
\end{array}$ & $\mathbf{P}$ & $x$ & $\mathbf{N}$ & $\mathbf{P}$ & $\mathbf{P}$ & $\mathbf{N}$ & $\mathbf{P}$ & $\mathbf{N}$ & $\mathbf{P}$ & $\mathbf{P}$ & $\mathbf{P}$ \\
\hline & Tamanho dos grupos & $\mathbf{N}$ & $\mathbf{x}$ & $\mathbf{N}$ & $\mathbf{N}$ & $\mathbf{N}$ & $\mathbf{N}$ & $\mathbf{P}$ & $\mathbf{N}$ & $\mathbf{N}$ & $\mathbf{P}$ & $\mathbf{P}$ \\
\hline & $\begin{array}{c}\text { Presença de moradores em Unidades de Conservação } \\
\text { de Uso Sustentável }\end{array}$ & $\mathbf{P}$ & $\mathbf{x}$ & $\mathbf{P}$ & $\mathbf{P}$ & $\mathbf{P}$ & $\mathbf{P}$ & $\mathbf{P}$ & $\mathbf{P}$ & $\mathbf{P}$ & $\mathbf{P}$ & $\mathbf{P}$ \\
\hline & $\begin{array}{c}\text { Atividades recreativas e em contato com a natureza e } \\
\text { turismo ecológico }\end{array}$ & $\mathbf{P}$ & $\mathbf{x}$ & $\mathbf{P}$ & $\mathbf{P}$ & $\mathbf{P}$ & $\mathbf{P}$ & $\mathbf{P}$ & $\mathbf{P}$ & $\mathbf{P}$ & $\mathbf{P}$ & $\mathbf{P}$ \\
\hline & $\begin{array}{c}\text { Atividades socioculturais em unidades de conservação } \\
\text { de Uso Sustentável }\end{array}$ & NA & $x$ & $\mathbf{P}$ & $\mathbf{P}$ & $\mathbf{P}$ & $\mathbf{P}$ & $\mathbf{P}$ & $\mathbf{P}$ & $\mathbf{P}$ & $\mathbf{P}$ & $\mathbf{P}$ \\
\hline & Eventos & $\mathbf{P}$ & $\mathbf{x}$ & $\mathbf{P}$ & $\mathbf{P}$ & $\mathbf{P}$ & $\mathbf{P}$ & $\mathbf{P}$ & $\mathbf{P}$ & $\mathbf{N}$ & $\mathbf{N}$ & $\mathbf{P}$ \\
\hline \multirow{11}{*}{$5^{\circ}$} & Acesso Motorizado & $\mathbf{P}$ & $\mathbf{x}$ & $\mathbf{P}$ & $\mathbf{N}$ & $\mathbf{P}$ & $\mathbf{P}$ & $\mathbf{P}$ & $\mathbf{P}$ & $\mathbf{N}$ & $\mathbf{N}$ & $\mathbf{P}$ \\
\hline & Dificuldade de acesso & $\mathbf{P}$ & $\mathbf{x}$ & $\mathbf{P}$ & $\mathbf{P}$ & $\mathbf{P}$ & $\mathbf{P}$ & $\mathbf{P}$ & $\mathbf{P}$ & $\mathbf{P}$ & $\mathbf{P}$ & $\mathbf{P}$ \\
\hline & Estradas & $\mathbf{P}$ & $\mathbf{x}$ & $\mathbf{P}$ & $\mathbf{N}$ & $\mathbf{P}$ & $\mathbf{N}$ & $\mathbf{N}$ & $\mathbf{N}$ & $\mathbf{N}$ & $\mathbf{N}$ & $\mathbf{P}$ \\
\hline & Trilhas & $\mathbf{P}$ & $\mathbf{x}$ & $\mathbf{P}$ & $\mathbf{P}$ & $\mathbf{P}$ & $\mathbf{P}$ & $\mathbf{P}$ & $\mathbf{P}$ & $\mathbf{N}$ & $\mathbf{N}$ & $\mathbf{P}$ \\
\hline & Sinalização e Interpretação nas Trilhas & $\mathbf{N}$ & $\mathbf{x}$ & $\mathbf{N}$ & $\mathbf{N}$ & $\mathbf{P}$ & $\mathbf{N}$ & $\mathbf{P}$ & $\mathbf{N}$ & $\mathbf{N}$ & $\mathbf{N}$ & $\mathbf{P}$ \\
\hline & Edificações e equipamentos facilitadores & $\mathbf{P}$ & $x$ & $\mathbf{N}$ & $\mathbf{N}$ & $\mathbf{P}$ & $\mathbf{P}$ & $\mathbf{P}$ & $\mathbf{P}$ & $\mathbf{R}$ & s & $\mathbf{P}$ \\
\hline & Permoite & $\mathbf{P}$ & $\mathrm{x}$ & $\mathbf{P}$ & $\mathbf{P}$ & $\mathbf{N}$ & $\mathbf{N}$ & $\mathbf{P}$ & $\mathbf{P}$ & $\mathbf{P}$ & $\mathbf{s}$ & $\mathbf{P}$ \\
\hline & Sanitários e lixo. & $\mathbf{N}$ & $x$ & $\mathbf{P}$ & $\mathbf{N}$ & $\mathbf{s}$ & $\mathbf{N}$ & $\mathbf{P}$ & $\mathbf{P}$ & $\mathbf{s}$ & $\mathbf{s}$ & $\mathbf{P}$ \\
\hline & Acessibilidade & $\mathbf{P}$ & $x$ & $\mathbf{P}$ & $\mathrm{s}$ & $\frac{P}{P}$ & $\mathbf{N}$ & $\mathbf{P}$ & $\mathbf{P}$ & $\frac{N}{N}$ & $\mathrm{~s}$ & $\mathbf{P}$ \\
\hline & Presença Institucional & $\mathbf{P}$ & $x$ & s & $\mathbf{N}$ & $\mathbf{N}$ & $\mathbf{N}$ & $\mathbf{P}$ & s & $\mathrm{s}$ & $\mathrm{s}$ & $\mathbf{P}$ \\
\hline & Delegação de serviços & $\mathbf{P}$ & $x$ & $\mathbf{P}$ & $\mathbf{N}$ & $\mathbf{N}$ & $\mathbf{N}$ & $\mathbf{P}$ & $\mathbf{P}$ & $\mathbf{s}$ & $\mathbf{s}$ & $\mathbf{P}$ \\
\hline \multirow{2}{*}{$\begin{array}{l}\text { ACEITABILIDAD } \\
\text { E DOS } \\
\text { IMPACTOS } \\
\text { AMBIENTAIS } \\
\text { NEGATIVOS }\end{array}$} & a- Grau de impacto & $\mathbf{P}$ & $\mathbf{x}$ & s & $\mathbf{N}$ & s & s & s & $\mathbf{P}$ & $\mathbf{R}$ & N & $\mathbf{N}$ \\
\hline & b- Prevalência do Impacto & $\mathbf{P}$ & $\mathrm{x}$ & $\mathbf{N}$ & $\mathbf{N}$ & $\mathbf{N}$ & s & $\mathbf{N}$ & $\mathbf{P}$ & $\mathbf{R}$ & $\mathbf{N}$ & $\mathbf{N}$ \\
\hline \multirow{2}{*}{$\begin{array}{c}\text { ACEITABILIDAD } \\
\text { E DOS } \\
\text { IMPACTOS } \\
\text { SOCIAIS } \\
\text { NEGATIVOS }\end{array}$} & a- Grau de impacto & $\mathbf{P}$ & $x$ & s & NA & $\mathbf{P}$ & $\mathbf{P}$ & $\mathbf{N}$ & NA & NA & $\mathbf{P}$ & NA \\
\hline & b- Prevalência do Impacto & $\mathbf{P}$ & $\mathbf{x}$ & $\mathbf{s}$ & NA & $\mathbf{P}$ & $\mathbf{P}$ & $\mathbf{P}$ & NA & NA & $\mathbf{P}$ & NA \\
\hline
\end{tabular}


A partir dos resultados obtidos com a classificação de todos os atributos em todos os atrativos, nota-se que a grande maioria dos atributos proporciona classes de experiência pristina ou natural (Gráfico 2). E analisando o conjunto de atributos para cada atrativo separadamente, percebe-se também a predominância de atributos das classes pristinas ou naturais. Ou seja, os atrativos do PNCV analisados oferecem uma oportunidade de contato dos visitantes com a natureza extremamente preservada, com nenhuma ou pouca intervenção humana na paisagem e nos atrativos. Alguns poucos atrativos, tanto ao norte quanto ao sul, apresentam alguns parâmetros classificados como seminatural ou rural (Quadros 7 e 8), por estarem em um contexto de paisagem mais próximo à fazendas e áreas rurais, proporcionando diferentes classes de experiência.

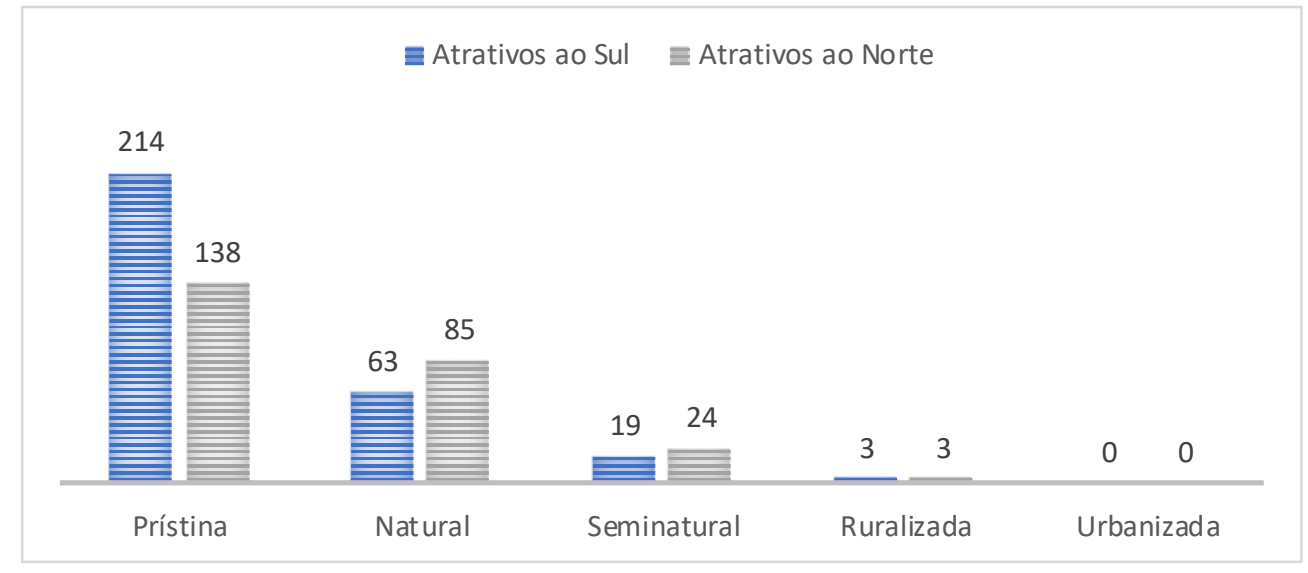

Gráfico 2: Classes de Experiência obtidas a partir do ROVUC. Graph 2: Classes of Experience obtained from ROVUC.

É interessante observar que mesmo sendo classificados predominantemente como pristinos ou naturais, cada atrativo tem uma composição distinta das diferentes classes de atributos (Gráficos 3 e 4), como Santana (Gráfico 3) e Barroco (Gráfico 4), com alguns atributos rurais, e outros como Caminho dos Veadeiros, Fiandeiras, Macacos, extremamente pristinos, no conjunto dos atributos.

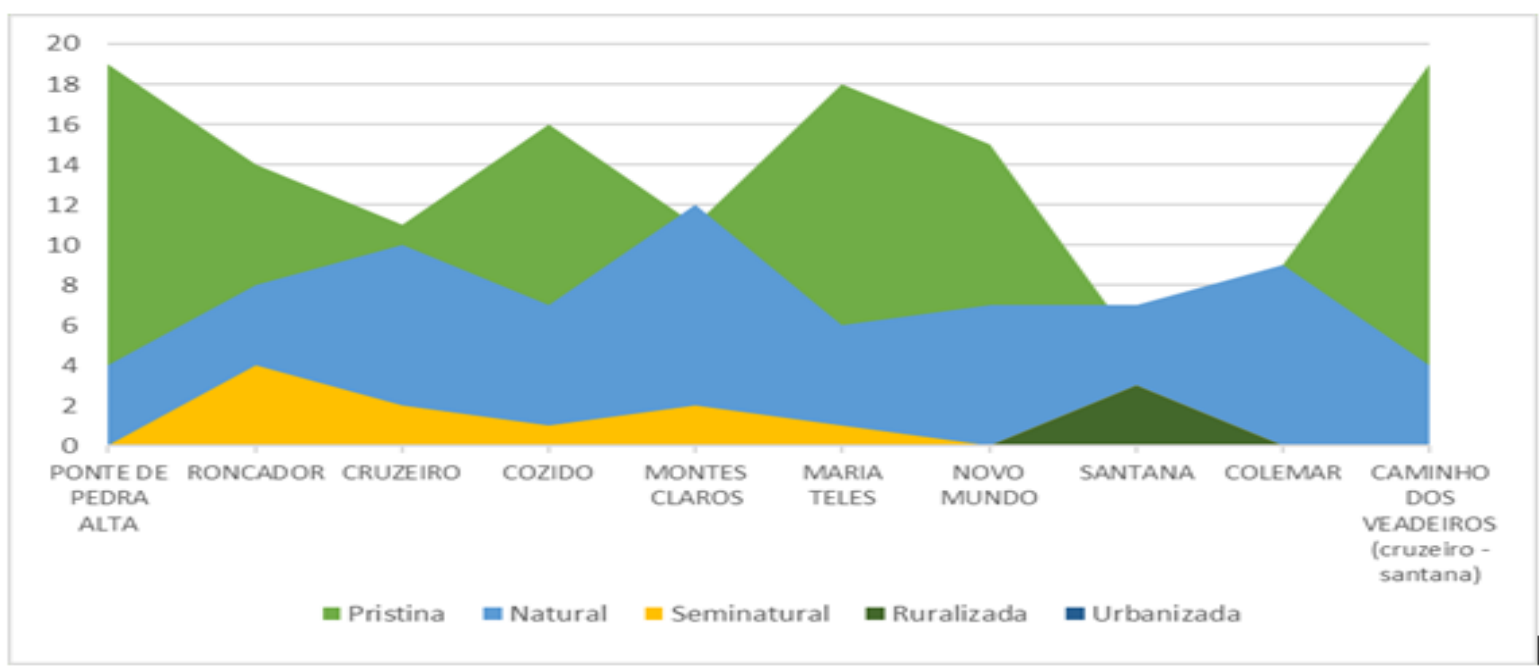

Gráfico 3: Classes de Experiência - Atrativos ao Norte do Pouso Alto.

Graph 3: Classes of Experience - Attractions in the North of Pouso Alto. 


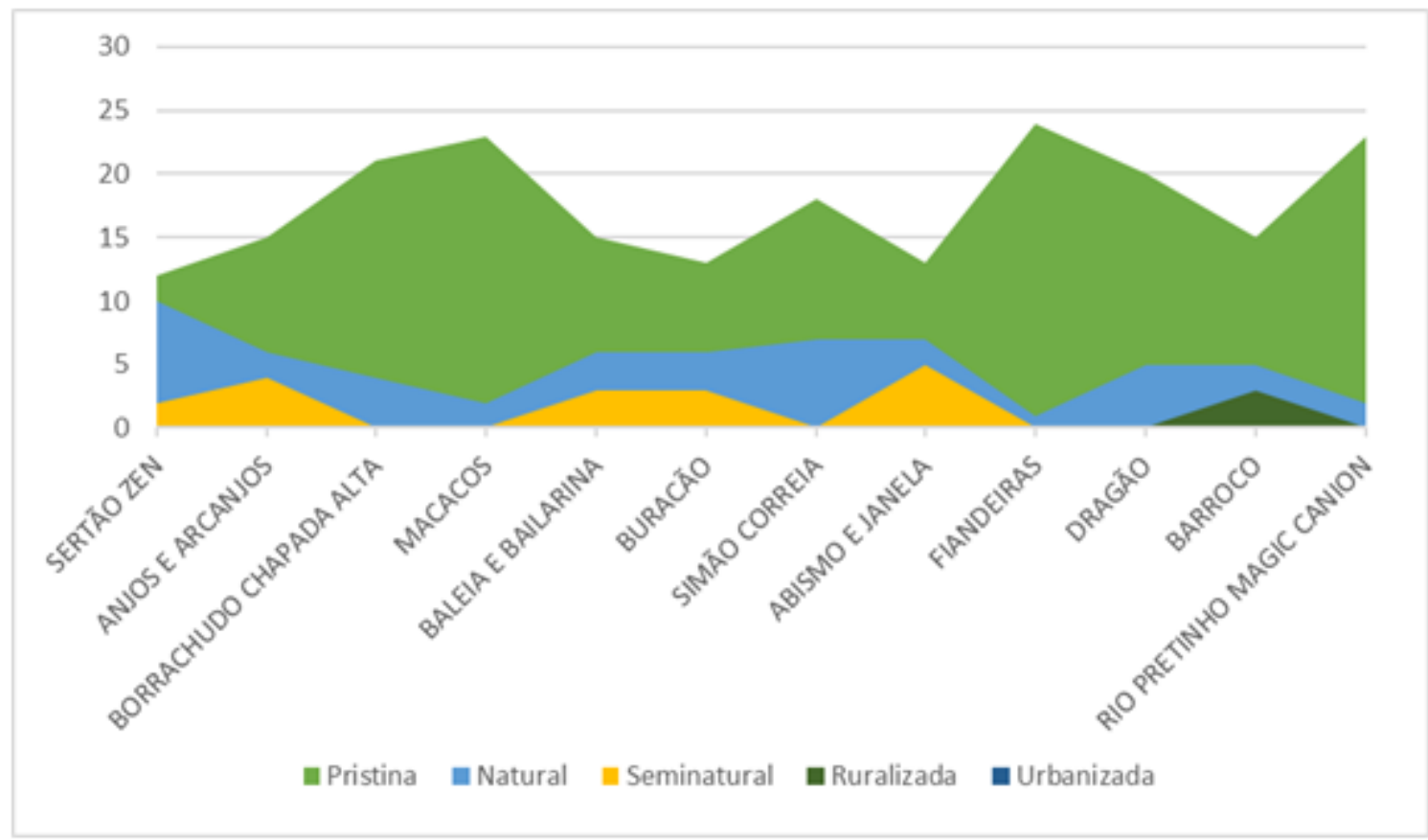

Gráfico 4: Classes de Experiência - Atrativos ao Sul do Pouso Alto.

Graph 4: Classes of Experience - Attractions in the South of Pouso Alto.

Sobretudo, os resultados indicam uma classificação predominantemente "Prístina", para o conjunto de atrativos do PNCV, que é caracterizada por uma área com a máxima naturalidade, mínima intervenção humana e baixa presença de visitantes, conforme a classificação do ROVUC.

\section{Discussão}

A aplicação da ferramenta do ROVUC e a identificação de atividades foi realizada com sucesso, de acordo com as etapas estabelecidos para este trabalho (Figura 4). A parceria entre pesquisadores, gestores e guias locais proporcionou resultados satisfatórios e um ganho adicional em termos de aproximação, troca de experiências e um ambiente ainda maior de diálogo e fortalecimento para a gestão integrada do turismo de natureza. Embora as informações resultantes deste processo possam ser aprimoradas e detalhadas com trabalhos de campo em cada atrativo e com análises adicionais, consideramos que a quantidade e qualidade de informações sistematizadas aqui representam um grande avanço e importante subsídio para a gestão do uso público na UC. A abordagem utilizada neste estudo pode e deve ser replicada para outras áreas naturais no Brasil, por se tratar de uma aplicação viável, financeira e operacionalmente, no curto prazo, conforme previsto pelo ROVUC (ICMBio, 2018). Consideramos importante o uso dos parâmetros elencados no ROVUC e sugerimos a inclusão dos parâmetros adicionados neste estudo (Quadros 7 e 8) buscando resgatar, de acordo com as orientações originas do ROS (STANKEY; CLARK, 1979) mais atributos relacionados aos parâmetros ambientais e de sensibilidade aos impactos. Dado o número e peso, ou detalhamento desbalanceado entre os parâmetros de manejo comparado com os biofísicos e socioculturais, acreditamos que futuras revisões do ROVUC podem considerar maior número de 
parâmetros biofísicos e socioculturais. Sobretudo, a riqueza de informações e considerações a partir dos resultados alcançados, reforçam a relevância do presente trabalho, conforme detalhado a seguir.

\section{Atividades existentes e potenciais}

Existe uma grande gama de atividades ofertadas para os visitantes do PNCV. Para os atrativos com ordenamento do uso público trabalhados nas oficinas (Saltos e Carrosel, Cânios e Carioquinhas, e Travessia das Sete Quedas) os participantes identificaram ao menos 15 atividades que já são realizadas atualmente (Quadro 5), número superior as cinco atividades já catalogadas pela gestão. Assim, é preciso considerar a importância em trabalhar e criar momentos de trocas de informações entre a gestão, os guias, e pesquisadores, o que traz enriquecimento e maior coparticipação para a otimização do uso público. É importante também, que trabalhos futuros consultem e façam uma catalogação das atividades seguindo listagens já existentes (ver ICMBio 2020), para que seja possível padronizar e eventualmente comparar tais números. Sobretudo, é surpreendente a elevada quantidade e diversidade de atividades que já são e que ainda podem ser ofertadas aos visitantes do PNCV.

Muitas das oportunidades listadas como atuais, ou existentes, são feitas de forma esporádica e ainda preliminar. A operação de parte destas requer profissionais capacitados e normas de segurança específicas, que estão sendo tomadas em conta para que tais atividades sejam ofertadas e operacionalizadas com a devida adequabilidade. Nota-se também que a maior parte dos atrativos listados, inclusive com atividades já em curso, ainda não tem o uso público adequadamente ordenado, estão em diferentes pontos de acesso do PNCV e em diferentes situações fundiárias e históricas em relação à visitação. Considerando ainda a escassez de recursos humanos e financeiros do órgão gestor, torna-se um grande desafio para a gestão do uso público. Por outro lado, é uma oportunidade para diferentes modalidades de parcerias público privadas, para viabilizar recursos necessários para tal gestão e oferta adequada dos atrativos e diferentes oportunidades para visitação. A partir de um ordenamento do uso público mais adequado, e de um ambiente de negócios mais estimulante (NYBAKK; HANSEN, 2008) serão multiplicadas as possibilidades de empreendedorismo (BEETON, 2010), de experiências para os visitantes, e de benefícios econômicos para as comunidades do entorno (BERALDO, 2018). Investimentos em infraestrutura, no aprimoramento de serviços, de informação aos turistas e empreendedores, e o gerenciamento do turismo são pontos fundamentais para o desenvolvimento do ecoturismo, no setor norte e outras áreas do PNCV, assim como em diversas situações similares no Brasil e no mundo (NEUPANE; PANT, 2013).

Os atrativos ao sul do Pouso Alto oferecem uma variedade maior de atividades em relação aos atrativos do norte. Isto deve-se, em parte, ao fato de o portão principal da unidade ser localizado na área sul. E esta estar no eixo entre a cidade de Alto Paraíso de Goiás e a vila de São Jorge, onde estão os atrativos com ordenamento do uso público. É neste eixo que se concentram a maior parte dos atrativos e do fluxo de visitantes do PNCV e da Chapada dos Veadeiros como um todo. Há mais de uma década a abertura de um portão norte para acesso ao PNCV tem sido trabalhada pelo PNCV e parceiros locais, mas ainda não foi implementada. Este acesso norte, pela 
cidade de Cavalcante, trará diversos benefícios e oportunidades para a população local e em relação ao fluxo de visitação da Unidade. No somatório das atividades nos 11 atrativos da região norte, existem 33 atividades existentes $(A), 12$ incipientes $(A / P)$ e $110 \mathrm{com}$ potencial para serem realizadas (Quadro 4). Já nos 16 atrativos da região sul, foram listadas, um total de 112 atividades/atrativos existentes (A), 141 potenciais (P) e 69 incipientes (A/P) (Quadro 5) Esta diferença no total de atividades por atrativos e na relação atividades existentes/atividades potenciais reflete o maior tempo de atividade do turismo na região sul, assim como o maior tempo de exploração e de conhecimento dos guias e gestores sobre os atrativos dessa região. Por outro lado, reflete também o grande potencial da região norte, que pode ser ainda maior, como o maior conhecimento e tempo de exploração destes e de outros atrativos. Por fim, cabe ressaltar que este exercício preliminar foi feito para alguns atrativos selecionados nas regiões nos arredores da cidade de Alto Paraíso, vila de São Jorge e cidade de Cavalcante, com uma perspectiva de implementação nos próximos 15 anos. No entanto, existem vários outros atrativos nesta região, além de outros atrativos que devem ser explorados, estimulados e implementados nos arredores das cidades de Nova Roma, Teresina de Goiás, São João da Aliança e Colinas do Sul, que foram contempladas com a recente expansão do PNCV (BRASIL, 2017), e possuem belezas cênicas e vocações turísticas únicas e complementares àquelas já analisadas, e locais aonde uma das principais justificativas para a ampliação do parque foi a chegada ou a ampliação do turismo e dos benefícios decorrentes. Logo, estudos como esse devem ser aprimorados e complementados para estas regiões, como subsídio para elaboração do Plano de Uso Público do PNCV.

\section{Rol de Oportunidades de Visitação}

A abordagem do Recreational Opportunity Spectrum (STANKEY; CLARK, 1979) aplicada às unidades de conservação brasileiras, o Rol de Oportunidades de Recreação - ROVUC (ICMBio, 2018), foi aplicado com sucesso no PNCV, seguindo as orientações do ROVUC (ICMBio, 2018), e com o objetivo de diagnosticar a situação atual. A partir disso, é possível também utilizar essa ferramenta para planejar mudanças nas oportunidades de recreação a serem ofertadas, como proporcionar atrativos com maior nível de intervenção humana, como maior infraestrutura e serviços ofertados, condições de conforto, acessibilidade (ICMBio, 2018). O ROS, assim como o ROVUC podem ser utilizados para a modelagem de diferentes cenários de intervenção, manejo e mudança na paisagem (HARSHAW; SHEPPARD, 2013) Assim como avaliar medida de manejo visando atingir determinadas experiências dos visitantes a partir das oportunidades ofertadas (STANKEY; CLARK, 1979). Assim, realizar um inventário como este feito neste trabalho, é um primeiro passo para outras etapas do planejamento do uso público em uma área natural ou unidade de conservação.

A abordagem do ROS ou ROVUC pode ser feita em diferentes escalas espaciais. Recentemente, foi feita uma análise para os parques e florestas nacionais do Brasil, considerando atributos internos à UC e atributos do seu entorno e região, estas UCs foram classificadas em um gradiente, de áreas primitivas, semiprimitivas, extensivas, intensivas e altamente intensivas (SOUZA, et al., 2018). O PNCV foi classificado como intensiva no contexto interno, e extensiva no contexto externo e na 
classificação total, comparado a outras UCs, desde um contexto bastante remoto, como o Parque Nacional do Xamanxin, no Pará, até outro extremo como o Parque Nacional da Tijuca, no Rio de Janeiro (SOUZA, et al., 2018). Mas em um contexto local, dentro do PNCV, observamos que os atrativos e atributos são em sua maioria pristinos e naturais. É interessante ainda considerar o contexto regional, no qual a Chapada dos Veadeiros se insere, em que podemos observar atrativos em áreas externas ao parque, com características tipicamente seminaturais e rurais, como cachoeiras com ampla infraestrutura e serviços e hotéis fazenda em meio a natureza. Assim, é interessante considerar a abordagem do ROS em diferentes escalas espaciais. A partir do inventário realizado aqui, é interessante avaliar a realidade do Parque em relação a diversificação de áreas para visitação, levando em consideração que na região limítrofe do Parque já existem possibilidades diversas de visitação em classes diferenciadas. Nesse sentido, compreendeu-se que a classificação predominante por áreas e atributos prístinas, definida pelos participantes das oficinas, foi destacada como a principal vocação do PNCV, pelos participantes das oficinas, como um ambiente com menor intervenção humana na região. No entanto, deve-se considerar que o PNCV também é a principal área remanescente e representativa do bioma Cerrado. Logo, pode ser interessante manejar algum atrativo para proporcionar novas oportunidades de visitação para determinados públicos com demandas de infraestrutura e serviços mais desenvolvidos. Assim, este público pode ter contato com paisagens mais preservadas, e abordagens como a interpretação ambiental, podem resultar em transformações positivas desses visitantes, do ponto de vista da percepção do valor das UCs, das áreas naturais e por fim, das ações e comportamentos em prol do meio ambiente.

\section{Recomendações}

É aconselhável considerar possíveis ajustes no ROVUC (ICMBio, 2018), em relação aos atributos propostos. Dentre as principais lacunas observadas, destaca-se que os atributos biofísicos podem não ser suficientes para avaliar as especificidades destas áreas, enquanto os atributos socioculturais podem ser aprimorados para detalhar o contexto de diferentes UCs, particularmente as de Uso Sustentável. Considerando ainda que o ROVUC é um subsídio que influencia fortemente a definição do zoneamento das UCs federais, é importante considerar mais atributos relacionados aos valores de conservação e à sensibilidade dos ambientes e espécies frente à eventuais impactos negativos. Neste trabalho, como uma sugestão preliminar para suprir essas lacunas, sugerimos a inclusão de alguns indicadores apresentados nos resultados (Quadros 7 e 8).

Os atributos devem ser analisados no seu conjunto, mas também individualmente para cada atrativo, tanto em relação ao diagnóstico quanto as opções de planejamento e manejo. Ou seja, é possível manejar e caso necessário, ou desejável, alterar a classe de experiência de atributos individualmente em cada atrativo, como, por exemplo, a frequência, ou o tamanho dos grupos, a sinalização, as trilhas, a infraestrutura, os serviços, mas entendendo todo o conjunto de atributos daquele atrativo, assim como os demais atrativos da área, ou da UC, e da região. Sobretudo, a diversidade de atributos deve ser analisada em conjunto, e não é recomendável simplificar o conjunto de atributos em um único valor ou classe de experiência para cada atrativo (STANKLEY; CLARK, 1979). Caso isso seja feito, a 
necessidade de revisão é ainda maior, e a simples média ou somatório dos atributos não seria adequada, ainda mais dada a quantidade desigual de atributos nas três dimensões, biofísica, sociocultural e de manejo.

A princípio pode parecer interessante ampliar a diversidade de atrativos cobrindo várias classes de experiência nas UC e parque nacionais brasileiros. No caso do PNCV, manejar os atributos socioculturais e de manejo para proporcionar condições mais seminaturais e ruralizadas. No entanto, é importante compreender melhor as demandas dos visitantes e a capacidade de gestão da UC e seus parceiros, pois em geral, atributos em condições mais seminaturais, rurais e urbanas, demandam mais recursos humanos e financeiros, e uma gestão mais intensiva. Assim, é importante investir em pesquisas sobre os visitantes, o monitoramento das condições ambientais e dos atributos, as possíveis soluções em diferentes modelos de parcerias público-privadas, além de planejar o uso público como um todo, os investimentos para implantação e manutenção de infraestrutura, e o custo-benefício das diversas opções. No caso do PNCV, e de diversas outras UCs, ainda há o desafio de ordenar o uso público na maior parte dos atrativos onde já existe visitação e nos que ainda não há. É sabido que o inventário é um processo que carece de atualização permanente por lidar com realidades dinâmicas e em constantes transformações do processo de visitação, da capacidade e dos interesses da gestão das Unidades, dos parceiros, das políticas governamentais e até mesmo das exigências da própria área e das comunidades do entorno. Para isso, em se tratando de uma Unidade de Conservação tão extensa como a do PARNA Chapada dos Veadeiros, recomenda-se que a cada cinco anos, o método seja reaplicado para atualizar e validar as prioridades e as realidades existentes em cada atrativo listado como prioritário. Em relação às priorizações de planejamento para estes atrativos inventariados, sugere-se a aplicação de uma análise FOFA (SWOT) por considerá-lo um método utilizado no planejamento estratégico que será adequado para as necessidades de encaminhamento da proposta deste estudo, subsidiando o desenvolvimento de um plano de ação para a o uso público.

Por fim, destaca-se a importância do trabalho participativo entre a gestão do ICMBio, os guias de turismo e o Centro UnB Cerrado que foi de fundamental importância para a construção deste trabalho. Isso parece caracterizar o fortalecimento de uma ação sustentável na Unidade, no que diz respeito ao envolvimento da comunidade na tomada de decisões. Recomendamos, como próximos passos, que os resultados preliminares desta pesquisa sejam devidamente revisados pela equipe do PNCV, em parceria com os pesquisadores, e posteriormente devolvidos para comunidade, ampliando o convite para todo o segmento turístico e também buscando envolver todos os demais setores da sociedade, inclusive os não envolvidos nas atividades turísticas atualmente. E sempre que possível, ampliar o rol de participação dos atores ao longo do processo, de acordo com a dinâmica de trabalho que a região estabelecer ao longo dos anos. Não se sabe ao certo como funcionaria a dinâmica de trabalho caso o número de adesão da oficina fosse maior, mas, imagina-se que apesar de mais árduo em relação à mediação das oficinas, seria obtido um número ainda maior de informação e detalhes, oportunizando que outros participantes agregassem ainda mais particularidades ao trabalho. 


\section{Considerações Finais}

A pesquisa científica amparada por metodologias participativas possibilitou para este estudo a ampliação dos horizontes de discussão e trabalho referentes à diversificação de oportunidades de visitação no Parque Nacional da Chapada dos Veadeiros.

Os resultados aqui alcançados são respostas dos objetivos propostos no que diz respeito ao inventário das diferentes oportunidades de visitação existentes e potenciais, a classificação destes atrativos, a orientação sobre a diversificação da oferta de visitação e ainda para o auxílio na construção e implantação do Plano de Uso Público da Unidade.

Por meio do método utilizado, os resultados obtidos foram capazes de identificar e avaliar o Rol de Oportunidades de Visitação dos principais atrativos do PARNA Chapada dos Veadeiros para assim subsidiar a construção de um plano de uso público que traga elementos capazes de diversificar as oportunidades de visitação de acordo com a necessidade do público visitante e dos interesses da Unidade.

Para além dos objetivos propostos para este estudo, observou-se que o trabalho participativo dos guias de Turismo em parceria com a gestão da Unidade proporcionou maior riqueza e robustez às informações de inventário e classificação dos atrativos, bem como o estreitamento dos laços entre os atores envolvidos e principalmente para que os guias de turismo compreendessem a importância de sua atuação colaborativa para a gestão da Unidade. Mesmo não tendo aplicado nenhuma pesquisa relacionada à satisfação dos participantes em relação às oficinas, foi possível observar o estreitamento dos laços entre os envolvidos, e um ambiente ainda mais produtivo para o trabalho conjunto entre a gestão do PNCV e os guias de Turismo da Chapada dos Veadeiros.

\section{Agradecimentos}

Aos guias de turismo que participaram e aportaram valiosas informações. À toda equipe do PNCV, em especial F.Tatagiba, A. Ribeiro, M.C. Camargo pela parceria na elaboração e condução das oficinas, e juntamente com os voluntários do PNCV e R.Infante da Fazenda Miraflores pelo apoio logístico. A equipe da Coordenação de Uso Público pelas produtivas conversas no início do trabalho. Aos docentes e equipe do Centro UnB Cerrado, em especial W. Cavalcante por todo suporte para a realização das aulas da especialização e ao Laboratório de Biodiversidade e Áreas Protegidas pelo apoio durante a pesquisa.

\section{Nota:}

${ }^{1}$ Vista a urgência em se estabelecer áreas prioritárias para conservação ambiental imediata, em 1988, o ecólogo conservacionista britânico Norman Myers, foi o primeiro a incluir o conceito de Hotspots de biodiversidade no meio científico. Os denominados pontos quentes caracterizam-se por abrigar um número enorme da diversidade biológica da Terra além de alto endemismo de espécies, mas, em contrapartida, são também as regiões mais devastadas do planeta (OLIVEIRA; PIETRAFESA; BARBALHO, 2008) 


\section{Referências}

ANDRADE, T.C. A Experiência das Visitas Guiadas e Autoguiadas: Um Ensaio Interpretativo pelo Parque Nacional da Chapada dos Veadeiros - GO. Thamyris Carvalho Andrade, 2014.

BEETON, S. Regional community entrepreneurship through tourism: the case of Victoria's rail trails. Int. J. Innovation and Regional Development, v.2, no 1/2, 2010.

BRASIL. Decreto de 5 de junho de 2017. Amplia o Parque Nacional da Chapada dos Veadeiros, localizado nos Municípios de Alto Paraíso de Goiás, Cavalcante, Nova Roma, Teresina de Goiás e São João da Aliança, Estado de Goiás.

BRASIL. Decreto no 5.419 de 07 de maio de 2001. Dispõe sobre a criação da Área de Proteção Ambiental - APA de Pouso Alto e dá outras providencias.

BRASIL. Lei no 9985, de 18 de julho de 2000. SNUC, Sistema Nacional de Unidades de Conservação.

BRASIL. Plano de Manejo do Parque Nacional da Chapada dos Veadeiros. Brasília: 2009

HARSHAW, H.W.; SHEPPARD S.R.J. Using the recreation opportunity spectrum to evaluate the temporal impacts of timber. harvesting on outdoor recreation settings. Journal of Outdoor Recreation and Tourism; v.1, n.2: p.40-50. 2013.

ICMBIO - Instituto Chico Mendes. Disponível em: <www.icmbio.gov.br.html>. Acessado em 04 de novembro de 2018.

ICMBio. Mapa da Reserva da Biosfera. Disponível em: <http://www.icmbio. gov.br/parnachapadadosveadeiros/images/stories/reserva da biosfera/MAPA $1.1 \mathrm{R}$ ESERVA BIOSFERA.jpg >. Acesso em: 29 de novembro de 2018

ICMBio. Uso Público e Turismo. Disponível em: <http://qv.icmbio.gov.br/ QvAJAXZfc/opendoc2.htm?document=painel corporativo 6476.qvw\&host=Local\&ano nymous=true $>$. Acesso em: 01 de dezembro de 2018

KALTENBORN, B.P.; EMMELIN, L. Tourism in the high north: management challenges and recreation opportunity spectrum planning in Svalbard, Norway. Environmental Management, v.17, n.1, p.41-50, 1993.

LIMA, P.C.A.; FRANCO, J.L.A. As RPPNS como estratégia para a conservação da Biodiversidade: O caso da Chapada dos Veadeiros. Soc. \& Nat., v.26 n.1, p.113- 125. 2013

MORE, T.A.; BULMERS, S.; HENZEL, L.; MATES, A.E. Extending the recreation opportunity spectrum to nonfederal lands: an implementation guide. Gen. Tech. Rep. NE-309. Newtown Square, PA: U.S. Department of Agriculture, Forest Service, Northeastern Research Station, 25 p., 2003.

NASCIMENTO, D.T.F.; BRITO, B.N.; ÁVILA, R.C.; MELO, P.V.F. Caracterização Socioeconômica e Mapeamento Físico como Fomento à Gestão e ao Manejo da Reserva da Biosfera Goyaz - goiás/brasil. Geografia em Questão. Vol. 09. 2016

NEUPANE, R.; KC, A.; PANT, R. Assessing Tourism Potential In Bhaktapur Durbar Square, Nepal. International Journal of Environment, v;2, n.1, p.250-261, 2013. 
NYBAKK, E.; HANSEN, E. Entrepreneurial attitude, innovation and performance among Norwegian nature-based tourism enterprises. Forest Policy and Economics. Volume 10, Issues 7-8, October 2008, Pages 473-479

OLIVEIRA, D.A.; PIETRAFESA, J.P.; BARBALHO, M.G.S. Manutenção da Biodiversidade e o Hotspots Cerrado. Caminhos da Geografia, v.9 p.101-114. 2008

PIRES, P.S. A dimensão conceitual do Ecoturismo. Turismo - Visão e Ação, ํo1, p. 75-91, 1998

RODRIGUES, C.G.O. O uso público nos Parques Nacionais: a relação entre as esferas pública e privada na apropriação da biodiversidade. Universidade de Brasilia. 2009

ROSA, A.N.; TOLENTINO, R.C. Plano de Manejo: Parque Nacional da Chapada dos Veadeiros. ICMBio/ MMA, Brasília, 2009.

ROVUC. Rol de Oportunidades de Visitação em Unidades de Conservação. 2018 (No prelo)

UNESCO - Organização das Nações Unidas para a Educação; Reserva da Biosfera do Cerrado; disponível em: http://www.rbma.org.br/mab/unesco 03 rb cerrado.asp. Acesso em 30/11/2018, p.01.

WASHINGTON, DC: U.S. Department of Agriculture Forest Service. General Technical Reprot NE-309.

Thamyris Carvalho Andrade: Universidade Federal do Tocantins, Arraias, TO, Brasil.

E-mail: thamyris.andrade@gmail.com

Link para o currículo Lattes: http://lattes.cnpq.br/5153279640080154

Thiago do Val Simardi Beraldo Souza: Instituto Chico Mendes de Conservação da Biodiversidade, Brasília, DF, Brasil.

E-mail: thiago.beraldo@icmbio.gov.br

Link para o currículo Lattes: http://lattes.cnpq.br/1271748094280177

André de Almeida Cunha: Universidade de Brasília, Brasília, DF, Brasil.

E-mail: cunha.andre@gmail.com

Link para o currículo Lattes: http://lattes.cnpq.br/4652288314258859

Data de submissão: 27 de janeiro de 2020

Data de recebimento de correções: 06 de fevereiro de 2020

Data do aceite: 06 de fevereiro de 2020

Avaliado anonimamente 